\title{
Ecosystem assessment of the North-Central Adriatic Sea: towards a multivariate reference framework
}

\author{
Marta Coll $^{1,2, *}$ Alberto Santojanni ${ }^{3,4}$, Isabel Palomera ${ }^{1}$, Enrico Arneri $^{3,4}$ \\ ${ }^{1}$ Institut de Ciències del Mar (ICM-CSIC), Passeig Marítim de la Barceloneta 37-49, 08003 Barcelona, Spain \\ ${ }^{2}$ Department of Biology, Faculty of Science, Dalhousie University, 1355 Oxford Street, Halifax NS B3H4J1, Canada \\ ${ }^{3}$ Istituto di Scienze Marine (CNR), Sede di Ancona, Largo Fiera della pesca 2, 60125 Ancona, Italy \\ ${ }^{4}$ Present address: FAO AdriaMed and MedSudMed projects, Viale delle Terme di Caracalla, 00153 Rome, Italy
}

\begin{abstract}
We analyzed data from catch statistics, scientific surveys and results from ecosystem models to assess main changes in marine resources of the North-Central Adriatic Sea (Central Mediterranean) from the mid 1970 s to the early 2000s. We then quantified food-web changes using these datasets and trophodynamic indicators. We applied time series trends and a Principal Component Analysis (PCA) to reduce the number of multivariate dimensions and to define ecosystem reference directions. To assess the correlation between ecological indicators and abiotic (human or environmental) factors, we used the non-parametric BIO-ENV procedure. Results illustrated a general decrease in the biomass and catch of target species with time, with a first phase of increasing catch and biomass of some organisms from the 1970s to the 1980s, a 'fishing down the food web' process during the 1980s, and a clear trend towards biomass and catch reductions during the late 1990s and early 2000s. These changes occurred in parallel with an increase in fishing effort and human development in the basin and changes in environmental factors such as an increase in the average annual sea water temperature, a decrease in the inflow of highly saline Mediterranean water into the Adriatic Sea, and changes in the atmospheric pressure at sea level. We found a high and significant correlation between ecological indicators and abiotic factors (in particular with human factors: fishing effort and the human development index). Results from the PCA summarized main ecosystem trends and could be used as a reference framework. These results complement traditional single-species fisheries assessments and inform on past trajectories and present ecological status of the North-Central Adriatic Sea.
\end{abstract}

KEY WORDS: Food-web model - Catch statistics - Biomass surveys - Trophodynamic indicators · Fishing impact · Environmental factors · Ecosystem-reference directions · Adriatic Sea · Mediterranean

\section{INTRODUCTION}

The Northern and Central Adriatic Sea constitutes the widest continental shelf in the Mediterranean Sea (Pinardi et al. 2006), and presents a high diversity of environmental conditions and a high biodiversity (Ott 1992). It is also a valuable fishing area within Europe (Bombace 1992). Changes of pelagic and benthic marine communities have been described in the Adriatic
Sea (e.g. Jukić-Peladić et al. 2001, Vrgoć et al. 2004). These changes are, at least in part, related to fishing (e.g. Pranovi et al. 2001, Bombace \& Grati 2007), environmental factors (e.g. Marasović et al. 1995, Dulčić et al. 1999, Santojanni et al. 2006a, Grbec et al. 2008), and other anthropogenic impacts such as eutrophication (e.g. Barmawidjaja et al. 1995, Sangiorgi \& Donders 2004). An ecosystem model representing the NorthCentral (NC) Adriatic Sea during the 1990s showed 
high fishing impacts on the ecosystem (Coll et al. 2007). The fitting of this model to data was used to hindcast changes of the ecosystem from 1975 to 2002 (Coll et al. 2009b).

Changes in marine resources due to natural or anthropogenic factors can be perceived at the foodweb level, and have the potential to affect the structure and function of marine ecosystems with consequences for the management of natural resources. Therefore, there is an increasing need for ecosystem-based studies to inform marine resources management. In the present study, we combined available data from the NC Adriatic Sea to describe the main changes of this Mediterranean ecosystem from the mid-1970s to the early 2000s. Our goals were (1) to summarize major patterns of species abundance using complementary data sources and describe food-web structure and functioning changes using trophodynamic indicators, (2) to assess ecosystem change patterns defining a multivariate framework, and (3) to explore the evolution of these changes in relation to additional abiotic indicators (such as fishing effort, human development, and environmental factors).

This study presents novel results that complement previous work (Coll et al. 2007, 2009b) with the analysis and integration of temporal changes of the NC Adriatic Sea food web using complementary data sources. The availability of different data sets and the existence of ecological models provide an ideal opportunity to explore ecological patterns and chances in this Mediterranean Sea ecosystem, while accounting for differences in the data quality and data features. This work constitutes an important effort in terms of recent historical data collection from the 1970s for the Adriatic Sea. The reconstruction of historical food-web changes in the long-exploited and biologically rich Mediterranean ecosystems, while trying to determine the role played by ecosystem drivers and key species, presents the opportunity to determine responses of Mediterranean marine ecosystems to human impacts and climatic change.

\section{MATERIALS AND METHODS}

Area of study. The Northern and Central Adriatic Sea study area (Fig. 1; south limit of Vieste harbour) constitutes a wide continental shelf. The substrate is characterized by muddy to sandy bottoms. Owing to river runoff and oceanographic conditions, the region exhibits a decreasing trend of nutrient concentration and production from north to south and from west to east (Fonda Umani 1996). Numerous studies describe the distribution and abundance of marine fauna and flora of the Adriatic Sea (e.g. Riedl 1983, Županović \& Jardas 1989, JukićPeladić et al. 2001). It is an important area for the reproduction of small pelagic fish (Agostini \& Bakun 2002, Morello \& Arneri 2009) and a strategic region for marine vertebrate conservation (e.g. Zotier et al. 1999, Bearzi et al. 2004).

Datasets. Catch statistics: Landing statistics from 1975 to 2000 were obtained from official Italian sources (Istituto Nazionale Italiano di Statistica [ISTAT] and Istituto Ricerche Economiche per la Pesca e l'Acquacoltura [IREPA]). This dataset was corrected by incorporating discard information (Wieczorek et al. 1999, Cingolani et al. 2000, Cooper et al. 2000, Affronte \& Scaravelli 2001, Santojanni et al. 2005) and estimates of illegal, unregulated or unreported landings (Mattei \& Pellizzato 1996, Santojanni et al. 2001, 2005, Cingolani et al. 2002a,b, E. Arneri et al. unpubl. data). The estimates were also corrected using independent catch data collected from the Istituto di Scienze Marine-Sede di Ancona (ISMAR-CNR) to consider anchovy and sardine catches from 1975 to 2005 from the eastern Adriatic coast (Slovenia and Croatia) (Santojanni et al. 2005, 2006a,b). Aquaculture and catches from artisanal fisheries in the immediate coastal area were also excluded from the analysis. Demersal catch data from 2001 to 2005 were not included due to the different taxonomic resolution compared to the previous available data.

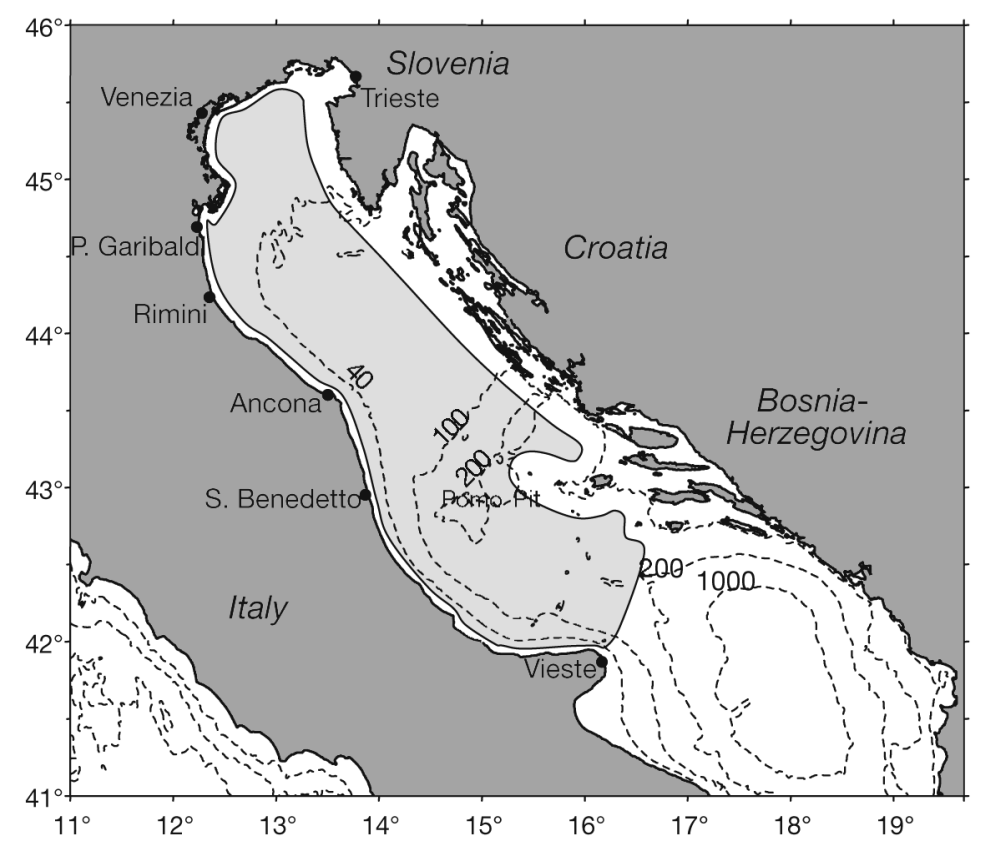

Fig. 1. Northern and Central Adriatic Sea. Study area: light grey 
Abundance and biomass time series data: Independent data on benthic diversity and biomass estimates were obtained from scientific trawl surveys conducted from 1982 to 2005 (GRUND surveys). These data were collected from the Adriatic basin covering the Italian territorial and international waters of the Adriatic Sea from 0 to $200 \mathrm{~m}$ depth and were conducted in the autumn using the Italian commercial fishing net (Vrgoć et al. 2004). Species reported included demersal and pelagic fish, crustaceans and molluscs (Table A1). Estimates of total biomass for anchovies and sardines from 1975 to 2005 were included in the analysis of species trends as well. These data were calculated by the ISMAR-CNR using a virtual population analysis tuned with echo-survey data (Santojanni et al. 2005, 2006a,b).

Modelling outputs: The mass-balance model describing an annual average situation for the NC Adriatic Sea during the mid-1990s (Coll et al. 2007) was adapted to represent the ecosystem in 1975 and was fitted to the available time series of data for 1975 to 2002 (Coll et al. 2009b). The trophic modelling tool Ecopath with Ecosim (EwE) version 5.1 (Christensen \& Walters 2004) was used to ensure the energy balance of the new model and to fit the model to data.

The ecological model of the NC Adriatic Sea comprised 40 functional groups or trophic species spanning the main benthic and pelagic components of the ecosystem from primary producers to top predators, including invertebrates, fish, birds, reptiles and marine mammals, and 2 detritus groups. The principal fishing activities in the area were included in the model: midwater trawling, bottom trawling, beam trawling, purse seine and tuna fisheries. Detailed description of the NC Adriatic model is provided in (Coll et al. 2007, 2009b). Time series of catch and biomass resulting from the model, and trophodynamic indicators were obtained using the model from 1975 to 2002, or the snapshot models from 1970s and 1990s (in the case of the keystoneness indicator) (Table 1).

Abiotic factors: Abiotic parameters included in the analysis were the following environmental factors: (1) sea surface water temperature (annual and winter mean ${ }^{\circ} \mathrm{C}_{i}$ Smith \& Reynolds 2004); (2) Po River runoff (annual mean, $\mathrm{hm}^{3} \mathrm{yr}^{-1}$ ) (SINAPSI project, Italian Ministry for research [MIUR]); (3) the North Atlantic Oscillation (NAO) Index (www.cgd.ucar.edu), both annual and winter values; (4) the Mediterranean Oscillation Index (MOI; Grbec et al. 2007); and human factors: (5) the Human Development Index (HDI; UNDP: http:// hdr.undp.org/en/statistics/data/); and (6) nominal fishing effort. Time series of nominal fishing effort of bottom trawling (including both beam and bottom trawling), mid-water trawling and purse seining were available in units of horse power (HP) and the number of boats per fishing harbour (ISTAT, IREPA and ISMAR-CNR). We aggregated the data to represent the NC Adriatic fleets. Trawling data were available from 1975 to 1995 through ISTAT and from 1996 to 2002 through IREPA. The 2 datasets did not align perfectly, so we extended the ISTAT series through 2002, extrapolating the general trend of the series observed in IREPA (see data in Coll et al. 2009b). Reliability of our procedure of interpolating ISTAT and IREPA data series was confirmed during the calibration process of our NC Adriatic model (Coll et al. 2009b).

Trophodynamic indicators. We used the above datasets to calculate selected trophodynamic indicators and to describe the food-web of the NC Adriatic Sea through time (Table 1). The first 6 indicators described below were applied to time series, while the last 2 were used to characterize different time periods of the ecosystem. These indicators were applied to catch statistics, scientific surveys and modelling results because we compared their trajectories, although their absolute values are not necessarily comparable between them since they may sample different fractions of the ecosystem. However, they can inform on similar or different trends. For example, the primary production required to sustain the catch (\%PPR) indicates the total amount of catch extracted from the system when calculated from fisheries data and modelling catch results, and informs on the total surveyed catch when calculated from scientific surveys. But a decreasing trend on this indicator from these 3 data sources may inform on a similar ecosystem process of depletion.

Biomass and catch trends and ratios: We analyzed biomass estimates from scientific surveys and those 
resulting from the model to explore species biomass trends $\left(\mathrm{t} \mathrm{km}^{-2}\right)$, and compared them with catch statistics $\left(\mathrm{t} \mathrm{km}^{-2} \mathrm{yr}^{-1}\right)$. We analyzed separately the data by commercial species (such as hake, Norway lobster and anchovy), while we analyzed the rest of the species in different ecological groups following Coll et al. (2007), such as crabs, shrimps, and benthic cephalopods. This aggregation enabled us to compare model results with scientific surveys and catch data due to the different aggregation of species in the 3 datasets.

In addition, we calculated the total demersal biomass to pelagic biomass ratio $(\mathrm{D} / \mathrm{P})$ as an indicator of the processes benefiting demersal or pelagic compartments. We included the total invertebrate to fish biomass ratio (Inv/Fish) as an indicator of change in the fish community. This ratio was expected to increase with fishing impact (Coll et al. 2009a), while D/P was expected to decrease with fishing, although it is also linked with other factors such as bottom-up effects (de Leiva Moreno et al. 2000) and changes in the pelagic compartment due to changes in the small pelagic fish populations.

Mean trophic level of the community and mean trophic level of the catch: The trophic level (TL) was first defined as an integer identifying the position of organisms within food webs (Lindeman 1942) and it was later modified to be fractional (Odum \& Heald 1975). Following an established convention, a TL of 1 is given to primary producers and detritus, the TL is formulated as follows:

$$
\mathrm{TL}_{j}=1+\sum_{j=1}^{\mathrm{n}} \mathrm{DC}_{j i} \cdot \mathrm{TL}_{i}
$$

where $j$ is the predator of prey $i, \mathrm{DC}_{j i}$ is the fraction of prey $i$ in the diet of predator $j$, and $\mathrm{TL}_{i}$ is the trophic level of prey $i$.

The mean trophic level of the catch $\left(\mathrm{mTL}_{\mathrm{c}}\right)$ reflects the fishing strategy in terms of selected food-web components, and was defined as the weighted average TL of harvested species (Pauly et al. 1998). The mean trophic level of the community $\left(\mathrm{mTL}_{\mathrm{co}}\right)$ reflects the structure of the community and was defined as the weighted average trophic levels (TL) of all species (Jennings et al. 2002). Both indicators generally decrease with increased fishing impact due to a reduction in the number of large predators and a relative increase in lower TL organisms. We calculated both indicators from modelling results, catch and biomass estimates. Moreover, we plotted total catches and the $\mathrm{mTL}_{\mathrm{c}}$ together following Pauly et al. (1998).

Fishing in balance index: The fishing-in-balance (FIB) index assesses whether catch rates are in balance with ecosystem trophic production due to catch at a given TL being related to assimilation efficiency of the ecosystem (Christensen 2000, Pauly et al. 2000). Therefore, one can expect higher catches at lower TL due to higher production at lower trophic levels. The FIB index is formulated as follows:

$$
\mathrm{FIB}=\log \left[\left(\sum_{i} Y_{i k} 10^{\mathrm{TL}_{i}}\right) /\left(\sum_{i} Y_{i 0} 10^{\mathrm{TL}_{i}}\right)\right]
$$

where $Y_{i k}$ is the catch of species $i$ during the year $k_{i} Y_{i 0}$ is the catch of species $i$ during the year at the start of a time series and which serves as an anchor; $\mathrm{TL}_{i}$ is the trophic level of species $i$, and 10 represents the bydefault mean transfer efficiency of the ecosystem, i.e. that $10 \%$ of the production of one trophic level is converted into the production of the next trophic level. A FIB index of zero indicates higher production at lower $\mathrm{TL}$, so fishing is in balance. A positive FIB value indicates that the fishery has expanded, or that bottom-up effects are occurring, so there is more catch than expected. The FIB index falls below zero when discarding occurs and discarding is not considered in the analysis, or when the fishing impact is so high that the ecosystem function is impaired (Christensen 2000, Pauly et al. 2000).

Primary production required to sustain the catch: The PPR typically measured as $\mathrm{t} \mathrm{km}^{-2} \mathrm{yr}^{-1}$, is obtained by back-calculating the flows, and is expressed in primary production and detritus equivalents for all pathways from the exploited species down to the primary producers and detritus (Pauly \& Christensen 1995):

$$
\mathrm{PPR}=\frac{1}{9} \cdot \sum_{i}\left[Y_{i} \cdot\left(\frac{1}{\mathrm{TE}}\right)^{\mathrm{TL}_{i}-1}\right]
$$

where $Y_{i}$ is the catch of a given group (i), TE is the mean transfer efficiency, $\mathrm{TL}_{i}$ is the trophic level of a group (i) and factor $1 / 9$ is taken as the average conversion coefficient from wet wt to gC. This index can be expressed per unit of catch relative to primary production and detritus of the ecosystem (\%PPR). Due to the fact that we were interested in the trajectory of this indicator but not the absolute value, we applied it to catch statistics, scientific surveys and predicted catch from modelling results (Table 1).

Loss in production index: The loss-in-production index (L index) quantifies the theoretical depletion of secondary production due to fishing in an exploited ecosystem and increases with fishing impacts (Libralato et al. 2008). This index was proposed as a proxy to characterize the effects of fishing on the ecosystem, and to estimate the probability that the ecosystem is being fished in a sustainable manner. The index takes into account both the properties of the ecosystem (the primary production [PP] and transfer efficiency [TE]) as well as the characteristics of fishing activity $\left(\mathrm{mTL}_{\mathrm{c}}\right.$ 
and \%PPR; Lindeman 1942, Pauly \& Christensen 1995, Pauly et al. 1998) as:

$$
\mathrm{L} \cong-\frac{\mathrm{PPR} \cdot \mathrm{TE}^{\mathrm{mTL}_{\mathrm{c}}-1}}{\mathrm{PP} \cdot \ln \mathrm{TE}}
$$

The L index can be used to estimate the probability that the ecosystem is being sustainably fished ( $P_{\text {susti }}$ Libralato et al. 2008). We applied this index to catch statistics and catch from modelling results (Table 1).

Modified Kempton's index of biodiversity: The modified Kempton's index of biodiversity (Q' index), or modified biomass diversity index, measures the relative index of biomass diversity based on the calculations proposed by Kempton's index expressing species diversity (Kempton \& Taylor 1976, Ainsworth \& Pitcher 2006). This index represents the slope of the cumulative species abundance curve between the 10th and 90th percentile, but since it is applied using functional groups and biomasses, the functional groups are considered equivalent to 'species', and their biomass the number of individuals (Ainsworth \& Pitcher 2006). The index is formulated as:

$$
Q^{\prime}=\frac{0.8 \cdot S}{\log \left(R_{2} / R_{1}\right)}
$$

where $S$ is the number of functional groups in the model or time series, and $R_{1}$ and $R_{2}$ are the biomass values of the 10th and 90th percentiles in the cumulative distribution curve. This indicator is expected to decrease with increasing fishing impacts.

Trophic spectra: Trophic spectra were calculated using TL per species or groups in ecological models, biomass estimates from scientific surveys, and from modelling results and catch statistics following Gascuel et al. (2005). This analysis provides a representation of an ecological property of the ecosystem (such as biomass or catch) per interval of TL by aggregating fixed TL intervals $(0.1 \mathrm{TL})$ of data and then using a weighted smoothing function over a fixed range of TL $(0.7 \mathrm{TL})$ to distribute the values of the data $(\Phi x)$ :

$$
\begin{aligned}
& \Phi \mathrm{x}\left(\mathrm{TL}^{\prime}\right)=\frac{1}{27} \cdot \mathrm{X}_{\mathrm{TL}^{\prime}-0.3}+\frac{3}{27} \cdot \mathrm{X}_{\mathrm{TL}^{\prime}-0.2}+\frac{6}{27} \cdot \mathrm{X}_{\mathrm{TL}^{\prime}-0.1} \\
& +\frac{7}{27} \cdot \mathrm{X}_{\mathrm{TL}^{\prime}}+\frac{6}{27} \cdot \mathrm{X}_{\mathrm{TL}^{\prime}+0.1}+\frac{3}{27} \cdot \mathrm{X}_{\mathrm{TL}^{\prime}+0.2}+\frac{1}{27} \cdot \mathrm{X}_{\mathrm{TL}^{\prime}+0.3}
\end{aligned}
$$

where $\Phi \mathrm{x}$ is the spectrum value of an ecological property (such as catch or biomass), TL' is a TL interval and $\mathrm{X}$ is the ecological property.

The keystoneness of trophic species: The keystoneness of trophic species (KS) was calculated for the mid1970s and mid-1990s using a method derived from the MTI analysis (Libralato et al. 2006) and the available ecosystem models (Coll et al. 2009b). The keystone species are those that show relatively low biomass but have a major structuring role in the ecosystem (Power et al. 1996). Keystone species can be identified by plotting the relative overall effect $\left(\varepsilon_{i}\right)$, calculated from the MTI, against $\mathrm{KS}_{i}$. The overall effect $\left(\varepsilon_{i}\right)$ is described as:

$$
\varepsilon_{i}=\sqrt{\sum_{j \neq i}^{\mathrm{n}} \mathrm{m}_{i j}^{2}}
$$

where $\mathrm{m}_{i j}$ is calculated from the MTI analysis. Then, $\mathrm{KS}_{i}$ of a functional group is calculated as:

$$
\mathrm{KS}_{i}=\log \left[\varepsilon_{i}\left(1-\mathrm{p}_{i}\right)\right]
$$

where $\mathrm{p}_{i}$ is the contribution of the functional group to the total biomass of the food web. This index is high when functional groups (species or groups of species) have both low biomass proportions within the ecosystem and high overall effects, in line with the keystone species definition.

Statistical analysis and comparison of indicators. We applied a simple linear trend analysis applying generalized least-squares regression following Coll et al. (2008b) to assess the significance of the increases or decreases in standardized ([indicator value in yearmean]/SD) time series of species abundance, trophodynamic indicators, and abiotic indicators. Time series of indicators are frequently characterized by strong autocorrelation, imposed as a consequence of the ecosystem dynamics. Thus, we fit a linear trend model to each of the time series using a generalized leastsquares regression framework, which models the temporal correlations in the error using a 2-stage estimation procedure to take into account the autocorrelation in the residuals and to satisfy regression assumptions. We then assessed the significance of the estimated trend (whether the predicted slope was significantly different from zero). This allowed for valid inference to assess the significance of the trend and compare the indicators.

We compared results from the KS and trophic spectra between the periods analyzed: 1970 s and 1990s. In addition and to integrate the rest of the available ecosystem information, we applied a principal component analysis (PCA) on the correlation matrix (Jongman et al. 1999) using biotic metrics to reduce the number of multivariate dimensions to a smaller set of linear combinations that explained the most variance. This analysis provided further delineation of key processes affecting the ecosystem through time and tracked major trends across the ecosystems. Changes in the PCA scores through time were evaluated as graphical ecosystem-reference directions following Link et al. (2002). Some model results had been obtained using the ecosystem model and forcing it with fishing effort and fitted to biomass series (Coll et al. 
$2009 b)$; thus, some of the time series were not independent from catch statistics and scientific surveys. Therefore, to avoid the redundancy in the data and compare the results of these 2 analyses, we first applied the PCA to catch statistics and scientific surveys (1982-2000), and after, to modelling results (1975-2002).

Finally, and to include in our analysis available information from abiotic indicators, we looked into the correlation between the ecological indicators and abiotic factors using the non-parametric statistical procedure BIO-ENV from PRIMER (Clarke \& Warwick 2001). This routine enabled us to identify the abiotic factors that globally best explained variability of the ecological indicators. This procedure calculated the correlation coefficients between similarity matrices of both ecological and abiotic indicators, and identified the combination of abiotic factors that maximized the correlation between ecological and abiotic similarity matrices.

Because the indicators represented different measures, we normalized the data prior to the construction of the Euclidean distance matrices (Clarke \& Gorley 2006). We then assessed skewness by constructing a draftsman plot (matrix of plots of each food-web property against the other) and the individual correlations between abiotic indicators examining the resulting Spearman rank correlations. We removed one of each pair of properties that were significantly correlated $(\rho \geq$ $0.95)$, thereby reducing redundancy and dimensionality of the data. Total fishing effort and fishing effort by trawling were highly correlated, as well as fishing effort by trawling and HDI. We removed fishing effort by trawling from the analysis.

\section{RESULTS}

\section{Biomass and catch trends by species}

Scientific surveys covering the period 1982-2005 showed a significant decline in crabs (Table A2) and benthic cephalopods and a significant increase in shrimps (Table A2, Fig. 2a). Catch statistics (19752000) showed a significant increase in crabs (Fig. 2C), while modelled biomass (1975-2002) of cephalopods, Norway lobster and 'other benthic invertebrates' group (Table A2) first increased and then decreased significantly (Fig. 2e).

Gadiforms, anglerfish, conger eels, demersal skates, demersal sharks and 'other demersal fish' group were found to decrease through time in various time series (Table A2, Fig. 2a, c,e,g), and for the group composed of 'other demersal fish', all the trends were significantly negative. Demersal skates, flatfish and anglerfish showed significant negative trends in 3 datasets.
Other gadiformes, conger eels, hake, red mullets and demersal sharks declined significantly with time in 2 of the time series analyzed. Anchovy, sardine, and the mixed group of small pelagic fish, horse mackerel and benthopelagic fish generally showed declining trends too (Table A2, Fig. 2b,d,f,h).

The time series for demersal skates and 'other demersal fish', including all the data sources (scientific surveys, catch statistics, and modelled biomass and catches) showed significant declining trends (Table A2). Moreover, benthic cephalopods, hake and other gadiforms, anglerfish, conger eel, flatfish, red mullets, 'other demersal fish', demersal sharks, horse mackerel, mackerel and benthopelagic fish showed significant decreasing trends in 2 time series of data from different data sources. Using the scientific surveys and catch statistics, we found a significant increasing trend in 2 data sets (Table A2): shrimps in scientific surveys and crabs in catch statistics.

Trend analyses showed that nearly all of the data series were highly auto-correlated and that in some cases, the normality and linearity assumptions were violated (Table A2). Although we only assessed linear trends, in general, catch statistics and modelled biomass and catches first showed an increasing trend until the early 1980s and then a decreasing trend (Fig. 2). Data from scientific surveys beginning in the early 1980s generally showed the decreasing trend (Fig. 2a,b).

\section{Total biomass and catch ratios, trophic levels and diversity index}

Total biomass and catch ratios reflected previous results and were found to decline with time (Fig. 3a). These declines were significant for total demersal biomass and catches from surveys and fisheries statistics, as well as for total pelagic catch and total catch from fisheries statistics, and total pelagic biomass from modelling simulations (Table 2).

The D/P catch ratio trend increased significantly when calculated from catch statistics (Fig. 3b, Table 2). The total invertebrate and fish biomass followed a declining trend that was significant when using modelling results. The Inv/Fish ratio showed a significant increase through time calculated from catch data (Fig. 3c). Total biomass and catch trends increased until the early 1980s and then decreased (Fig. 3).

The $\mathrm{mTL}_{\mathrm{co}}$ showed a significant decline through time when calculated from modelled biomass (Table 2, Fig. 3d). Both the $\mathrm{mTL}_{\mathrm{c}}$ from statistics and modelling results showed declines through time, although these trends were non-significant (Fig. 3e) and $\mathrm{mTL}_{\mathrm{c}}$ first increased from the early 1980s to the early 1990s. 
Pelagic species

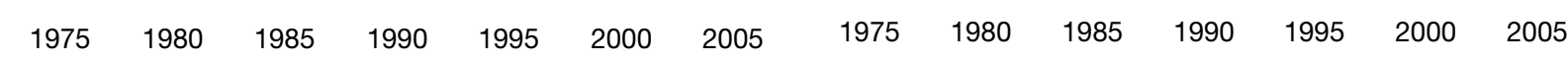

Scientific surveys
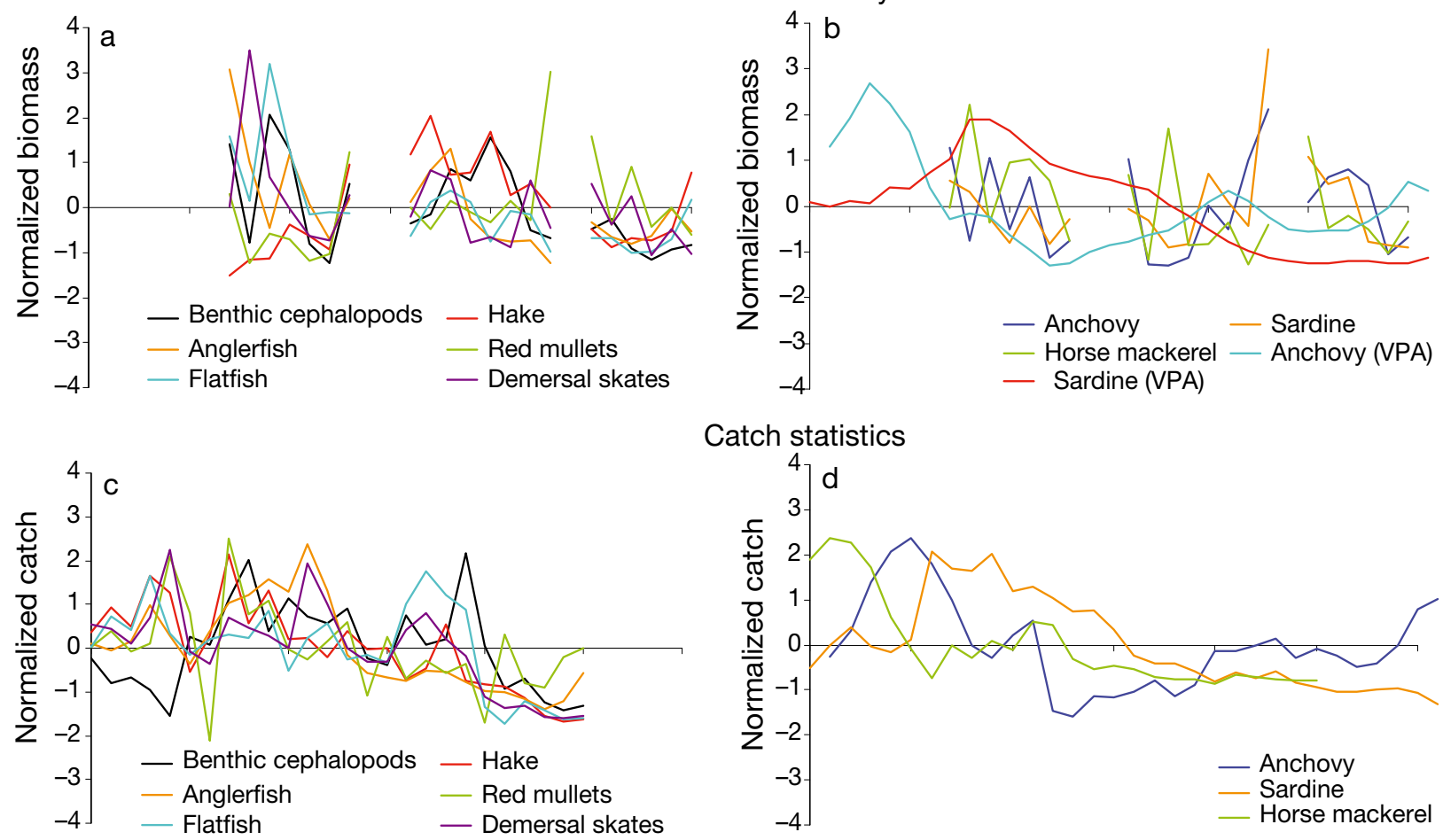

Catch statistics

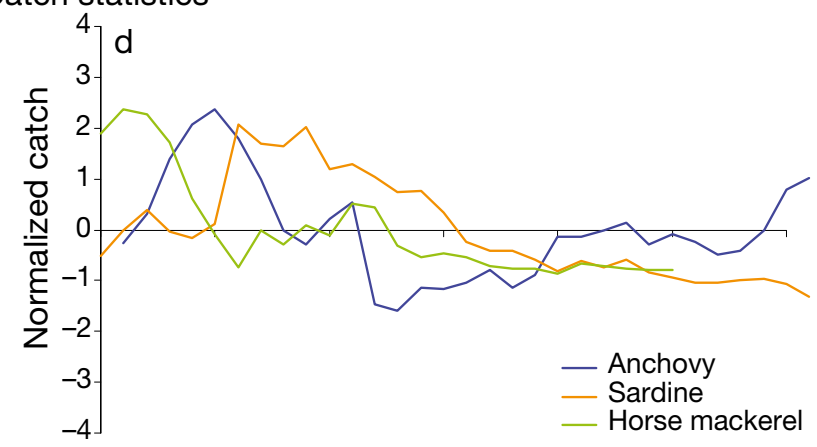

Modelling results: biomass
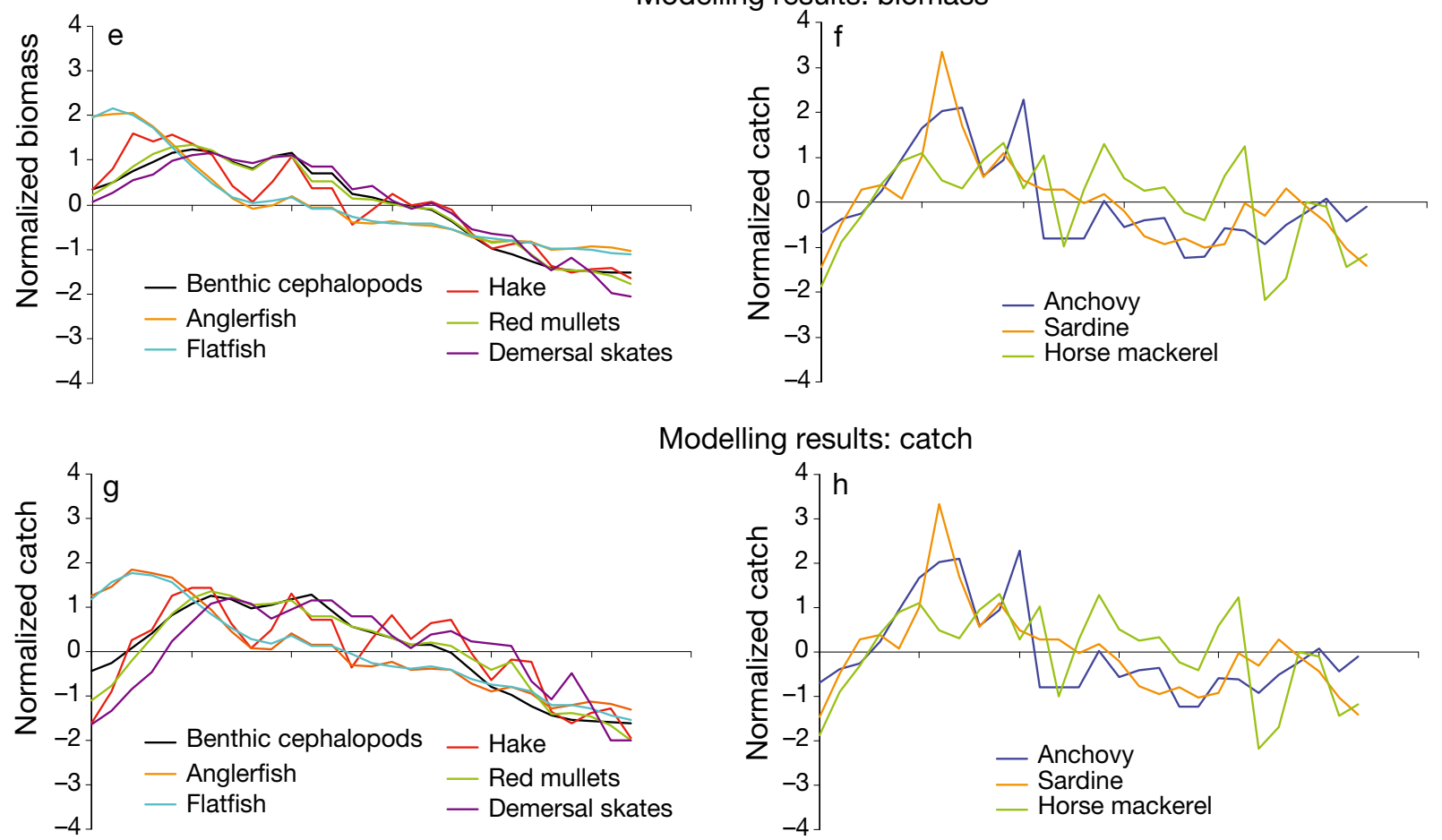

Modelling results: catch

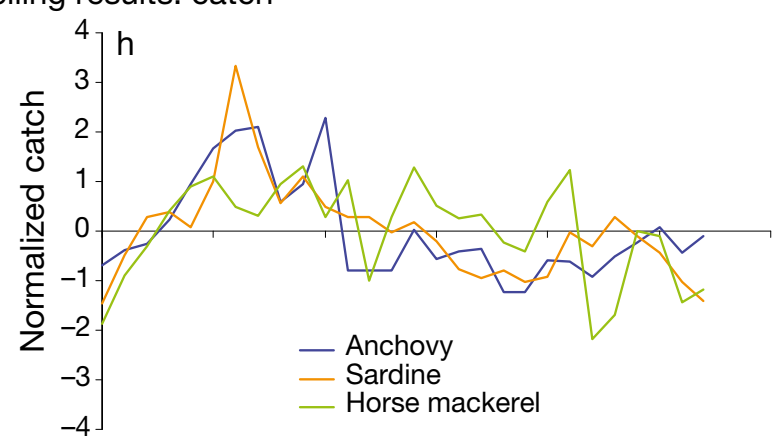

Fig. 2. (a,c,e,g) Demersal and (b,d,f,h) pelagic target species. Biomass and catch estimated from scientific surveys. (c,d) Catch statistics. $(\mathrm{e}, \mathrm{f})$ Modelled biomass. $(\mathrm{g}, \mathrm{h})$ Modelled catches. Statistical tests presented in Table A2 

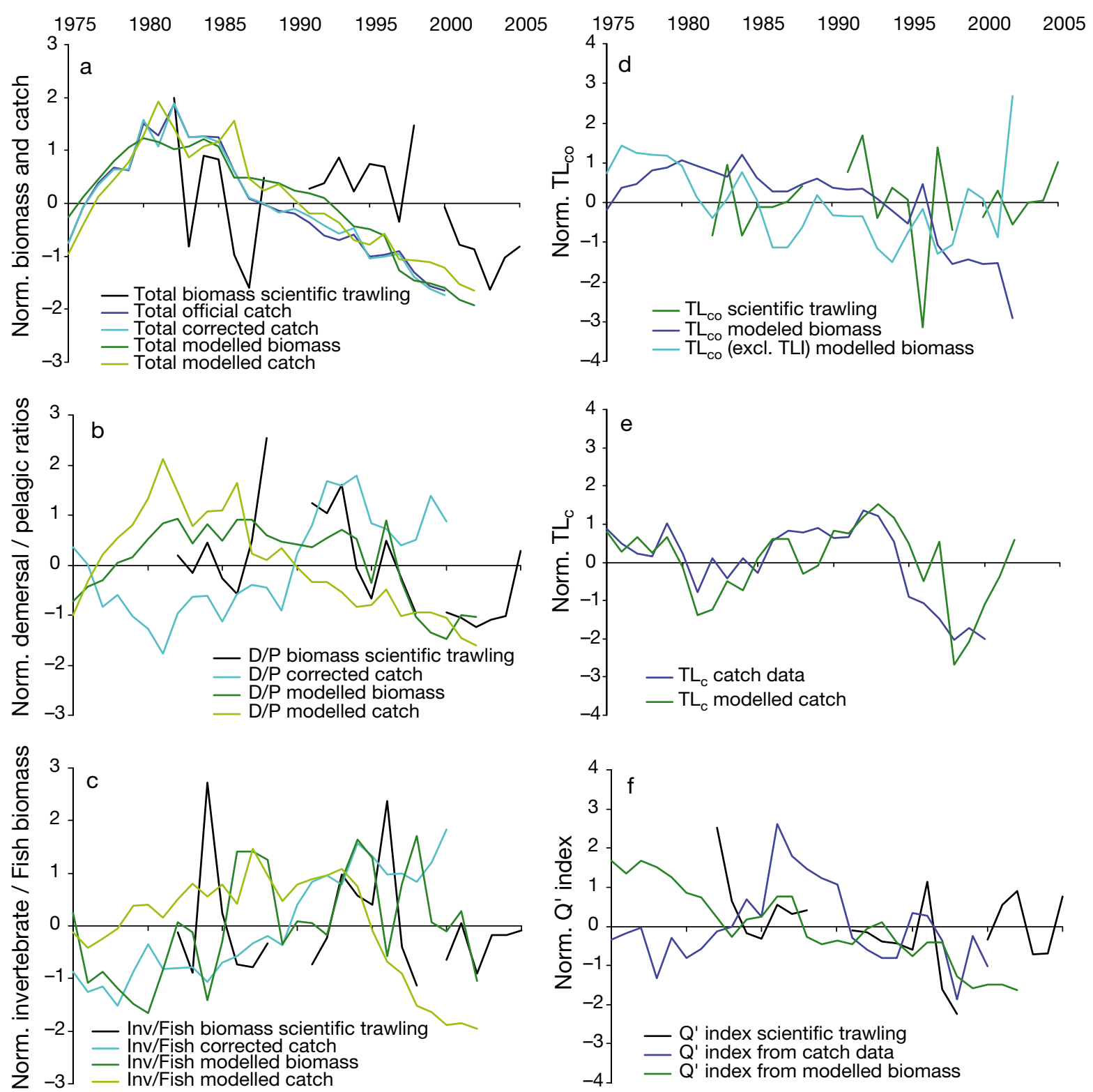

Fig. 3. (a,b,c) Normalized (norm.) total biomass and catch ratios estimated from scientific surveys, catch statistics, modelled biomass estimates, and modelled catches. D: demersal, P: pelagic, Inv: invertebrates. Mean trophic levels of (d) community (mTL $\left.\mathrm{m}_{\mathrm{co}}\right)$ and (e) catch $\left(\mathrm{mTL}_{\mathrm{c}}\right)$. (f) Kempton's modified index of biodiversity ( $\mathrm{Q}^{\prime}$ index), estimated using scientific surveys, catch statistics, and results from modelling

The $\mathrm{Q}^{\prime}$ index declined in all time series (Fig. 3f), and these declines were significant when calculated from modelling results.

\section{Primary production required, fishing in balance and loss of production}

The \%PPR calculated from scientific surveys data, catch statistics and modelling outputs showed a decline through time that was significant for both catch and modelling data (Table 2, Fig. 4a).
The FIB index showed significant declining trends in all cases (Table 2, Fig. 4b). The FIB index from catch data and modelling outputs also showed an increase through time until the early-mid 1980s, when it progressively declined until becoming negative in the mid 1990s. The FIB index was negative for all years when calculated from scientific surveys.

The L index also declined with time, although not significantly (Table 2, Fig. 4c). The probabilities $P_{\text {sust }}$ were $<75 \%$ and $50 \%$ when results were calculated from modelling and catch data, respectively, showing an increasing trend until the early 1980s and then a decrease. 


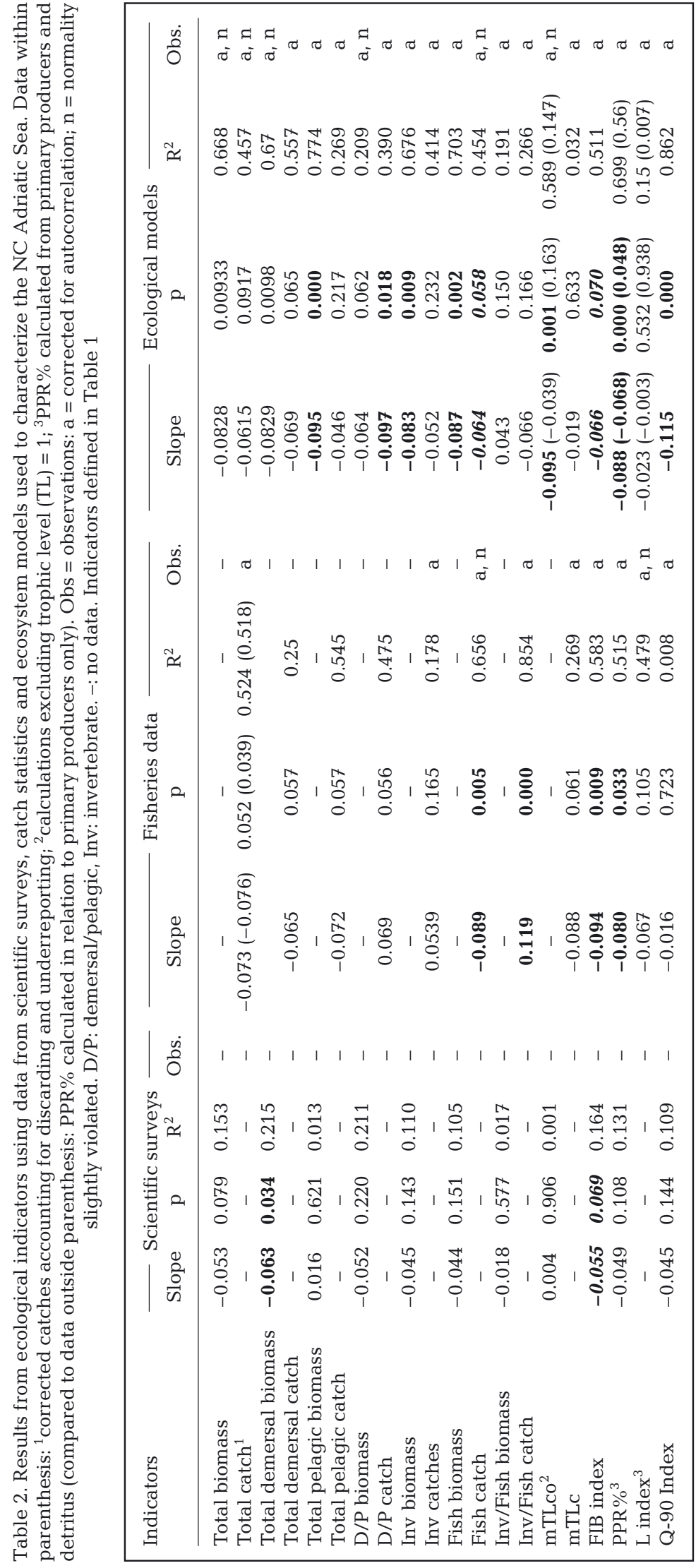

\section{Trophic spectra and the KS index}

The trophic spectra of catches from the NC Adriatic Sea expressed the year average catch each 5-yr using fisheries statistics from 1975 to 2000 and showed an increase from 1975 to the 1980s in all TLs, but especially in the lower TLs (Fig. 5a). There was then a progressive decrease of catches from the 1980s to 2000s, where lower catches were seen for all the TL. Trophic spectra of biomass estimates from scientific trawling surveys showed a decrease in the biomass of lower TL through time (TL 2.7-3.7) (Fig. 5b). There was also an intense decrease observed at TL $>4.5$, while the biomass of organisms with intermediate TL (3.8-4.3) increased from 1982 to 2005 . The trophic spectra of the modelled biomass showed an increase in biomass at lower TL (2-2.5) from 1975 to 1980 and then a progressive decrease until 2002 (Fig. 5c). Biomass at intermediate TL (2.5-3.5) increased from 1975 to 1985 and then declined until 2002. Lower biomasses were observed at all TL in the 2000s.

Keystoneness showed similar results for both time periods (Fig. 6). However, dolphins, squid and sardines decreased in terms of their importance from the 1970s to 1990s (Fig. 6a), and benthic invertebrates, mackerel and phytoplankton increased to become among the most important groups in terms of total effects and keystoneness (Fig. 6b).

\section{Plots of catch and biomass versus trophic level}

When plotting total catch versus the mTL of the catch by year, using data from catch statistics, a very clear pattern emerged (Fig. 7a). From 1975 to 1982, there was a decrease in the $\mathrm{mTL}_{\mathrm{c}}$ and an increase in catches, followed by a reversal, from 1982 to 1992. Afterwards, a progressive and marked decrease in the $\mathrm{mTL}_{\mathrm{c}}$ and in catches was observed until 2000. This general pattern was also observed when plotting the predicted catch and the $\mathrm{mTL}_{\mathrm{c}}$ from the modelling results (Fig. 7b), although an increase of the $\mathrm{mTL}_{\mathrm{c}}$ and a further decrease in the catches was described from 1998 to 2002. This pattern varied when plotting the total biomass and the commu- 

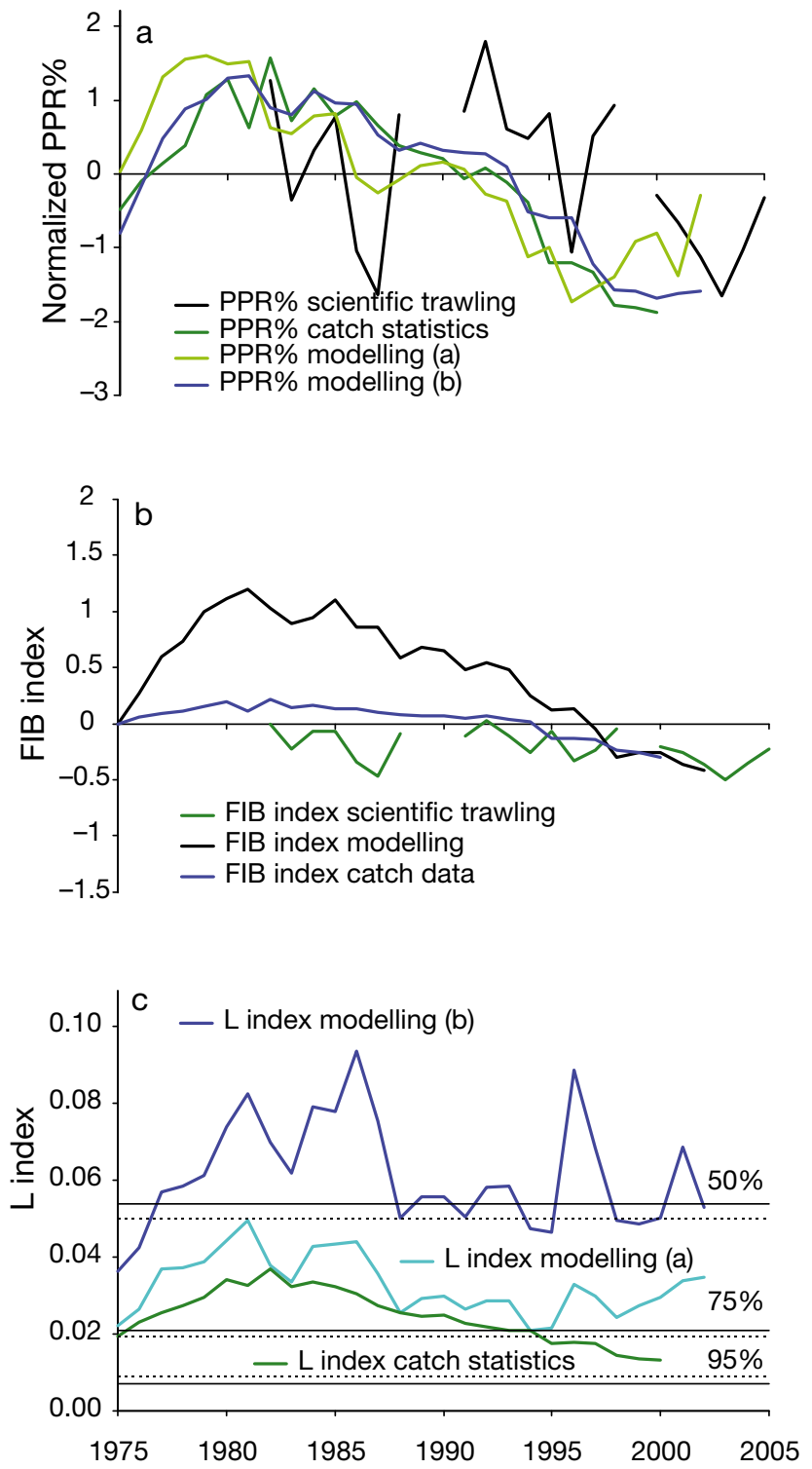

Fig. 4. (a) Primary production required to sustain the observed catch (PPR\%); (b) fishing in balance (FIB) index; and (c) loss in production due to fishing (L index), respectively, estimated from scientific surveys, catch statistics, modelled biomass, and modelled catches. L index was calculated from the modelling exercise considering: production from (1) primary producers and (2) primary producers and detritus. Reference levels of 50,75 and $95 \%$ probability that system is sustainably fished: dashed lines for (a), solid line for (b)

nity's $\mathrm{mTL}_{\mathrm{co}}$ obtained from modelling results (Fig. $7 \mathrm{C}$ ). The $\mathrm{mTL}_{\text {со }}$ and biomass increased from 1975 to 1984 , and afterwards there was a progressive decline in both until 2002. We did not observe any pattern when plotting scientific surveys data and the $\mathrm{mTL}_{\mathrm{co}}$ (results not shown).
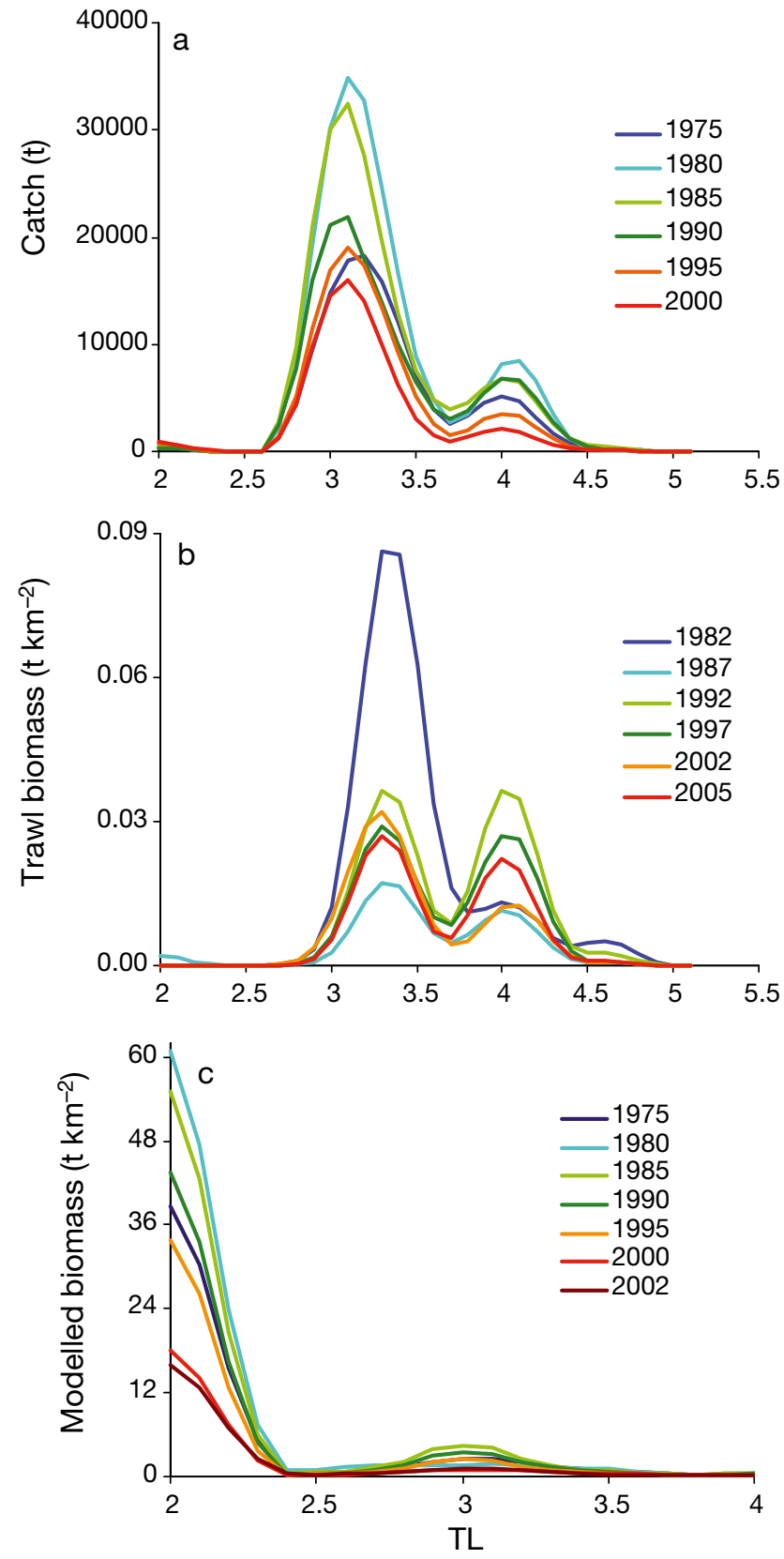

Fig. 5. Trophic spectra of the NC Adriatic Sea expressed by intervals representing average years of (a) corrected catch data (t) from 1975-2000; (b) trawl biomass (t $\mathrm{km}^{-2}$ ) for 1982-2005; and (c) modelled biomass ( $\mathrm{km}^{-2}$ ) for 1975-2002

\section{Ecosystem assessment}

The first 2 factors of a PCA applied to all time series of catch statistics and scientific surveys reported in Table $2 \&$ A2, in which data were available for each year from 1982 to 2000 , explained the $72.9 \%$ of the total variance (Fig. 8a). The first factor was mainly defined by lower values of fish and invertebrate biomass and 

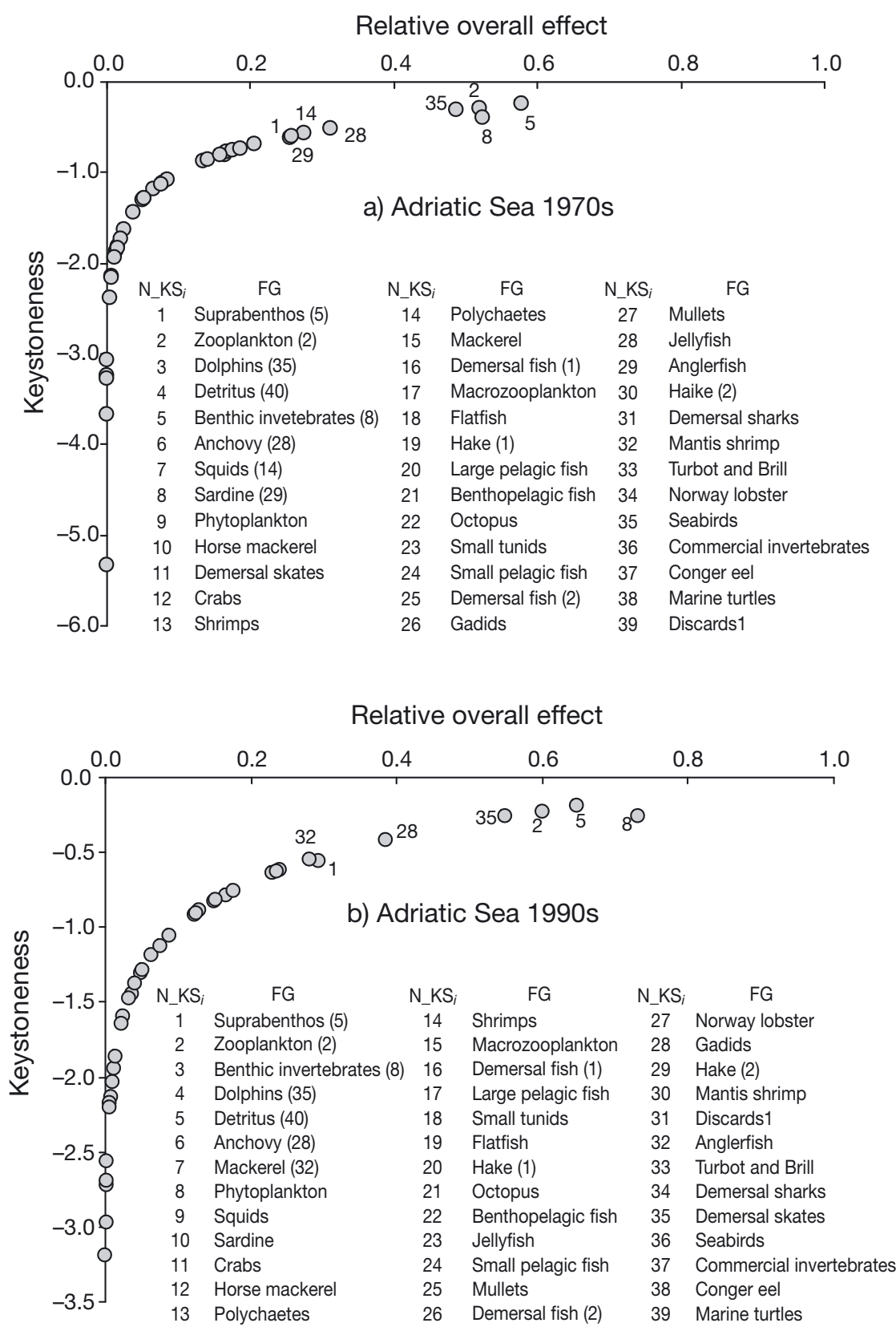

Fig. 6. Keystoneness index $\left(\mathrm{KS}_{i}\right)$ and overall effect $\left(\varepsilon_{i}\right)$ of each functional group (i) from the ecological model of the Adriatic Sea (Coll et al. 2009b) during (a) mid-late 1970s and (b) mid-late 1990s. Keystone groups are those with higher $\varepsilon_{i}$ and $\mathrm{KS}_{i}$ values (no species had KS close to or $>0$, Libralato et al. 2006). Numbers in parenthesis: functional groups (FG) identified in figure high biomass of benthopelagic fish, gadoids, cephalopods and FIB index. The second PC axis scores decreased from 1982 to 1987, then increased till 1998 and decreased again in 2000. The PC scores of the first 2 axes plotted throughout time showed a trend from the upper left to the upper right quadrat (Fig. 8a).

The first 2 factors of a PCA applied to all time series derived from modelling results reported in Table 2 \& A2 and abiotic indicators, with data available for each year from 1975 to 2002, explained the $88.4 \%$ of the total variance (Fig. 8c). The first factor was mainly associated with lower values of biomass and catch of fish and invertebrates, and lower values of all trophodynamic indicators (Fig. 8d). The first PC axis scores increased with time from 1975 to 2002, highlighting a general decline in biomass and catch. The second factor was mainly associated with high biomasses of anglerfish, flatfish, anchovy, benthopelagic fish, other small pelagic fish and catches of various groups, while there was a decrease in $\mathrm{L}$ index, $\mathrm{FIB}_{1} \mathrm{TL}_{\mathrm{co}}$, and catch and biomasses of various groups as well. The second PC axis scores decreased from 1975 to 1986 and then increased until 2002. The PC scores of the first 2 axes plotted through time showed a trajectory from the upper left to the upper right quadrate (Fig. 8c) as observed in the previous analysis (Fig. 8a).

\section{Abiotic indicators}

The regression model applied to the human and environmental indicators showed a significant increase of sea surface temperature (SST) $(p=0.000)$, and a decrease of MOI with time $(p=0.001)$ and SST in winter $(p=0.042)$. In parallel, there was an increase of the human development index (HDI) $(p=0.000)$ and of catches, but high levels of crab catch, shrimp and anchovy biomasses and high Invertebrate/Fish catch ratio (Fig. 8b). The first PC axis scores increased with time from 1982 to 2000, thus mainly highlighting the decrease of catch and biomass for most of the groups and proliferation of invertebrates. The second factor was defined by high L index (thus low $P_{\text {sust }}$ ) and total demersal biomass, fishing effort in the NC Adriatic Sea; the total fishing effort and the fishing effort of the trawling fleet increased significantly from 1975 to $2000(\mathrm{p}=0.000)$.

The first 2 factors of the PCA applied to all time series of abiotic indicators (1975-2002) explained the $51.8 \%$ of the total variance (Fig. 9a) and the first factor was mainly characterized by fishing effort (with higher 

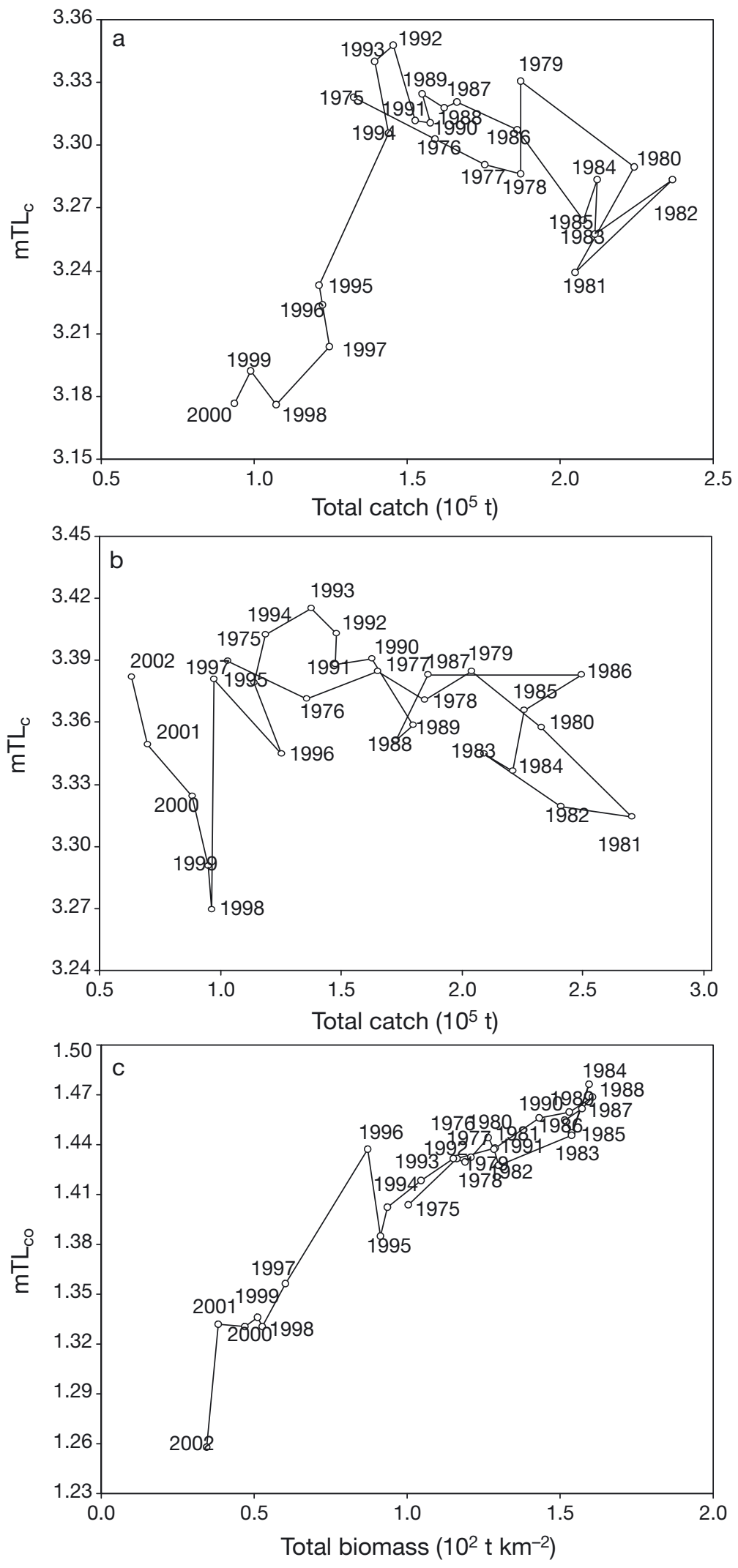

Fig. 7. Total catch and mean trophic level of the catch ( $\mathrm{mTL}_{\mathrm{c}}$ ) from (a) fisheries statistics, and (b) modelled catches. Total biomass and mean trophic level of the community $\left(\mathrm{mTL}_{\mathrm{co}}\right.$ ) from (c) modelled biomass values of total, trawling and purse seine fishing effort), by high values of annual SST (SSTt) and winter NAO (NAOw), and by low values of MOI and SSTw. The second factor was mainly characterized by environmental factors (higher values of NAO and SST, and lower of Po river runoff) (Fig. 9b). The PC scores of the first 2 axes plotted through time showed a trajectory from the upper left quadrate to the low right quadrate (Fig. 9a), and presented similarities with the previous ones observed in Fig. 8.

When correlating these abiotic data with the ecological indicators using the BIO-ENV test, we found positive significant correlations using both catch statistics and scientific surveys or modelling results (BIO-ENV test, correlation coefficient $\rho=0.862$ and 0.811 , and $p=$ 0.01 and 0.01 , respectively). The similarity matrices obtained with human indicators (fishing effort of purse seine, trawling and the HDI) correlated highest with the similarity matrix of ecological indicators from catch statistics and scientific surveys, illustrating that these abiotic indicators may be good predictors of the biotic indicators. Other environmental indicators such as Po river runoff, salinity and MOI contributed to the correlation matrix but lowering the overall correlation $(\rho=0.668)$. The similarity matrices of the human indicators obtained with total fishing effort and the HDI correlated highest with the similarity matrix of ecological indicators from modelling results. Other environmental indicators such as MOI or SSTt contributed to the correlation matrix but again lowered the overall correlation $(\rho=$ 0.661). These similarities are in line with the similar trends in the PCAs scores.

\section{DISCUSSION}

\section{Changes and drivers of biomass and catch in the NC Adriatic Sea}

The Adriatic Sea is one of the Mediterranean areas with a relative high availability of data. However, each data source used here had limitations that should be considered when interpreting results. Data from landing statistics were corrected to account for underreporting and discards, although the estimates were conservative (Coll et al. 2007). The scientific trawl biomasses were mainly demersal, and thus not adequate to capture 

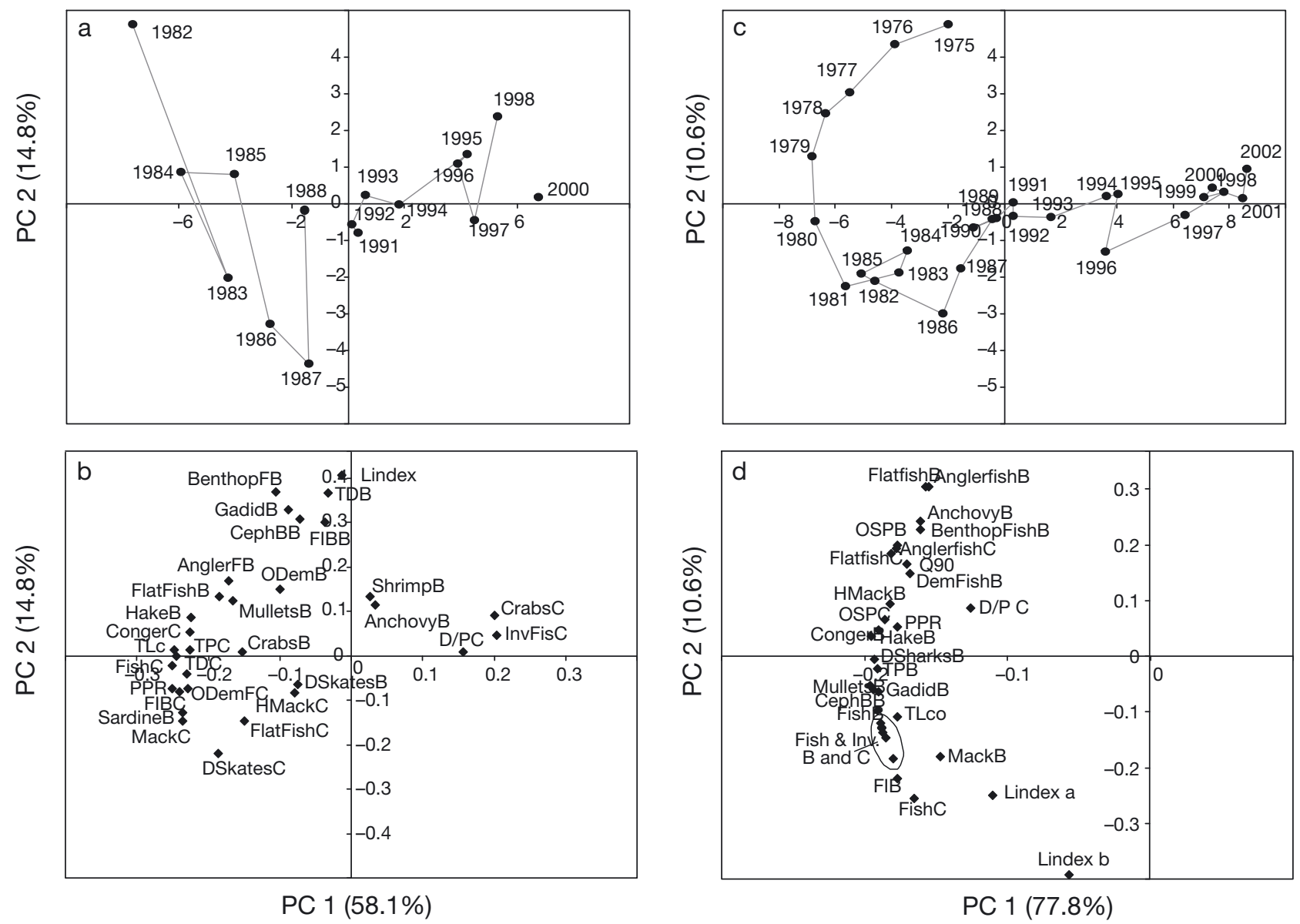

Fig. 8. Principal component (PC) analysis of NC Adriatic Sea indicators that illustrates temporal ecosystem changes. Analysis includes catch, biomass and trophodynamic indicators calculated with $(a, b)$ catch statistics and scientific surveys (1982-2000), or $(\mathrm{c}, \mathrm{d})$ with modelling predictions (1975-2002). Scores: 1st and 2nd PC indicating $\left(\mathrm{a}_{1}, \mathrm{c}\right)$ trajectory of ecosystem with time, and $(\mathrm{b}, \mathrm{d})$ indicators included in the analysis and their contributions to both PC. B: biomass, C: catch, OSP: other small pelagic fish, ODem: other demersal fish, TD: total demersal, TP: total pelagic, Inv: invertebrates, D/P: demersal/pelagic ratio, Q: Kempton's index

changes in pelagic species. They were mainly focused on fish species and a few commercial invertebrate species likely due to changes in protocol over the years (Table A1), so these data were not sufficient for analyzing changes in the lower trophic level organisms. On the contrary, these data were valuable for analyzing changes in the demersal fish community.

Main limitations on the modelling exercise are discussed in Coll et al. (2009b). The modelling data have by definition a 'built in' interpretation of the reality according to the Ecopath with Ecosim assumptions (Christensen \& Walters 2004). Therefore, it is not surprising that the analysis of trends of indicators from the modelling data series gave more clear and unambiguous results (Table $2 \&$ A2). Nevertheless, the 2 independent data sets (scientific surveys and official catch statistics) did not provide opposite signals to modelling results (see Figs. 2 to 5,7 \& 8, and Tables 2 \& A2), highlighting that modelling can provide additional hints on the ecosystem status when we face complex situations such as the one in the Adriatic Sea. Moreover, we used a basic linear model to assess the trend of time series and correct for autocorrelation. Our results suggested that most of the data were in fact autocorrelated, and only few trends showed violations of the regression assumptions in terms of non-stationarity and nonlinearity. A more sophisticated trend analysis could complement these results and show more details in the species patterns complementing the ecosystem assessment.

Despite these limitations, our results showed that there were important changes taking place in the NC Adriatic Sea from the mid-1970s to the early-mid 2000s. In several cases, 2 or 3 datasets showed decreasing trends in target species (illustrated by the first axis in the PCA analysis of Fig. 8). These results are in line with results from stock assessments indicating that several target and non-target demersal species are 


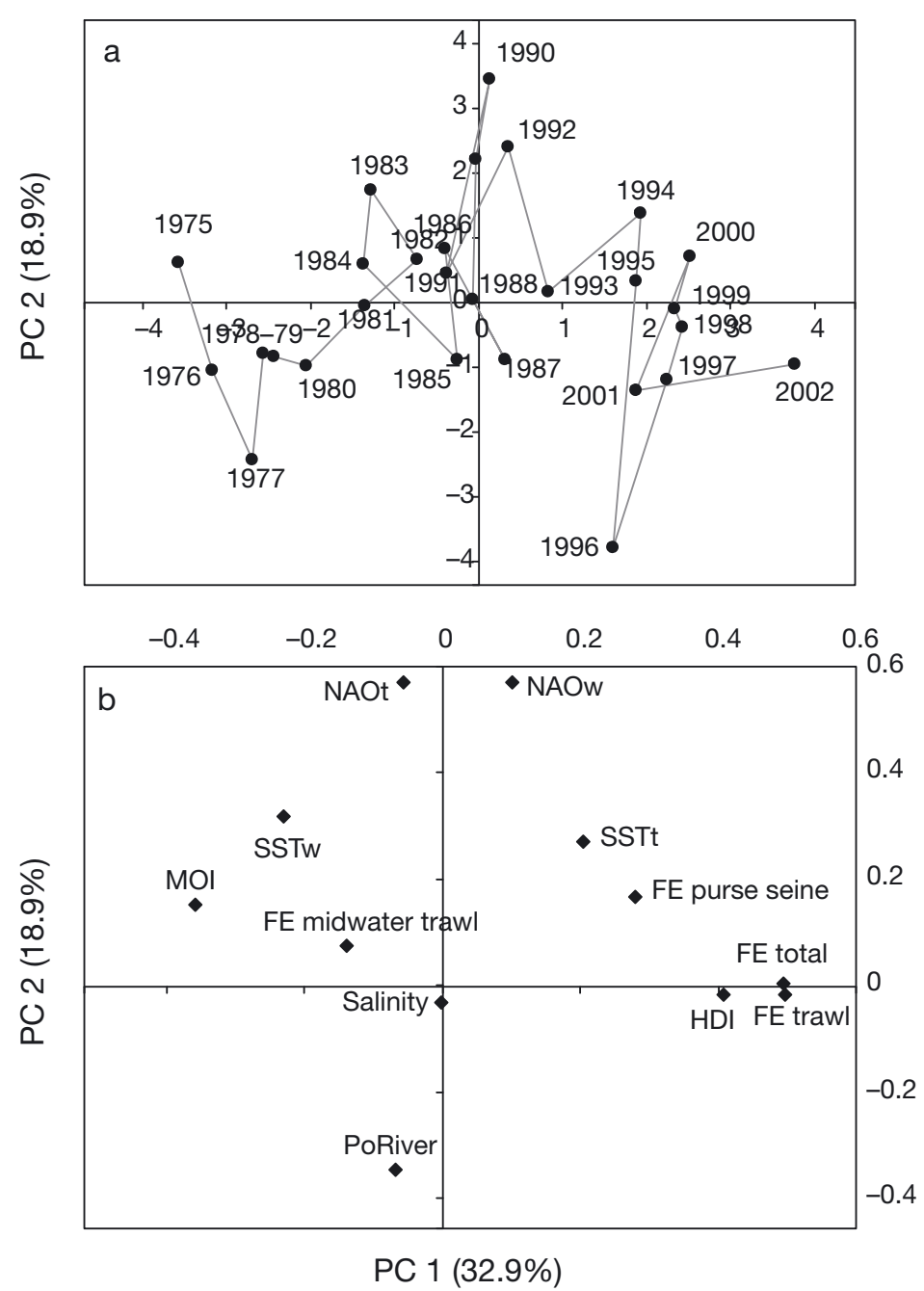

Fig. 9. Principal component (PC) analysis of abiotic indicators of the NC Adriatic Sea (1975-2002) including fishing effort (FE) by fleet, human development index (HDI) and environmental parameters such as Po river runoff (PoRiver), salinity, sea surface temperature (SST), Mediterranean Oscillation Index (MOI), and North Atlantic Oscillation Index $(\mathrm{NAO})$ (annual $=\mathrm{t}$; in winter $=\mathrm{w}$ ). Scores: (a) 1st and 2nd PC indicating trajectory of all these indicators with time, and (b) indicators included in the analysis and their contributions to both PCs

overexploited in the area (e.g. Jukić-Peladić et al. 2001, Vrgoć et al. 2004, Bombace \& Grati 2007).

Our results suggest that these trends occurred in parallel with a steady increase in fishing effort, as well as an increase in the HDI and changes in the environment, such as an increase in sea water temperature and changes in regional (e.g. MOI) and global (e.g. NAO) factors. These results are in line with previous studies in the Adriatic Sea analyzing some of these environmental indicators with more detail (e.g. Marasović et al. 1995, Dulčić et al. 1999, Grbec et al. 2002, 2003, 2007, 2008).

In addition to the general decreasing trends, we could observe that several biomass and catch series in- creased from the mid-1970s to the early 1980s, illustrated by the second axis of the PCA analysis of Fig. 8, before a strong decline was registered. This first increase could be due to indirect trophic effects such as trophic cascades (i.e. decrease in competition and predator release) as was described for the Catalan Sea (Coll et al. 2008b). The increase in catch and biomass during the 1970s could also be due to the increasing fishing effort, changing target species (e.g. towards invertebrate species), and/or to an increase of nutrient enrichment in the area. The eutrophication in the northern Adriatic Sea began in the 20th century, reached a maximum in the late 1970s, and levels were still high during the early 1990s (Sangiorgi \& Donders 2004). Barmawidjaja et al. (1995) analyzed benthic foraminifera records in the Northern Adriatic basin and described intense and prolonged anoxic events during the 1980s due to eutrophication. The eutrophication peak between 1978 and 1980 coincided with the peak in most of our time series (early 1980s); thus, the increase in biomass and catches up to this point and their consequent decrease could in part reflect patterns in eutrophication. During this period, the significant increase in fishing effort may have been compensated with higher production due to nutrient loading. A similar trend, an initial increase followed by a decrease, was observed in catch data from the Venice lagoon (Libralato et al. 2004) and was correlated with changes in nutrient loading.

\section{Changes in trophodynamics and ecological roles}

The changes of species biomass noted above had perceptible changes on the trophic relationships and ecological roles of species in the NC Adriatic ecosystem. Although no clear keystone species were identified during the study period (no species had $\mathrm{KS} \approx 0$ or $\mathrm{KS}>0$; Libralato et al. 2006), modelling results underlined the increasing importance of low and medium TL organisms in the Adriatic Sea ecosystem (e.g. suprabenthos, zooplankton, benthic invertebrates) due to their essential role in transfering energy to the higher TL. Anchovy was identified as an important species in the food web during both time periods analyzed; however, the important decrease of sardine with time was likely due to the decrease of biomass (Santojanni et al. 2003). These results are similar to the ones observed for the Southern Catalan Sea, NW Mediterranean from the late 1970s to the early 2000s (Coll et al. 2009a). 
Another interesting result was the decrease of cetaceans as keystone group in the ecosystem, which has also been observed in other marine ecosystems (e.g. California upwelling and Catalan Sea; Libralato et al. 2006, Coll et al. 2009a). This could be related to the decreasing population of these organisms in the Adriatic Sea (Bearzi et al. 2004).

Keystone analyses also showed the higher importance of phytoplankton in the mid-1990s in comparison to the mid-1970s, indicating that the ecosystem likely became more sensitive to changes in primary production and environmental forcing. The Adriatic Sea primary production is partially limited (Bosc et al. 2004) and is under the influence of local enrichment by river runoff, or changes in current circulation and in salinity that produce temporal upwelling areas associated with higher productivity (Agostini \& Bakun 2002). As previously discussed, overexploitation and simplification of food webs decrease the resilience of marine ecosystems and increase their vulnerability to environmental change (Hughes et al. 2005). This may also be the case for the Adriatic Sea.

\section{Food-web structure and fishing impacts}

In addition to the changes in abundance and ecological roles of marine species with time, we also documented changes in the structure and functioning of the NC Adriatic Sea ecosystem. Time series showed a general decrease in biomass and the $\mathrm{mTL}_{\mathrm{co}}$, suggesting that the ecosystem progressed from low abundance of large slow-growing organisms towards higher importance of small and fast growing organisms. This was also illustrated by the lower $\mathrm{mTL}_{\mathrm{c}}$ with time, lower $\mathrm{Q}^{\prime}$ index, higher Invertebrate/Fish catch and biomass ratios, and changes in the trophic spectra of the biomass and catch.

The indices (FIB, \%PPR, L) calculated using fishing statistics and model predictions increased through time due to fishery expansion and likely bottom-up effects (Christensen 2000) associated with eutrophication until the early-mid 1980s (Sangiorgi \& Donders 2004). A posterior decrease due to increased fishing effects on the ecosystems was observed in the FIB index, while negative values from the middle 1990s most likely indicated that the functioning of the ecosystem in terms of the upward transfer of production from low to high TL changed importantly (Pauly \& Watson 2005). Similar trends were shown for the FIB index when analyzing data from scientific surveys.

The bending backwards curve (Pauly et al. 2000) observed when plotting both the total catch and $\mathrm{mTL}_{\mathrm{C}}$ using fisheries statistics and modelling predictions illustrated a 'fishing down the Adriatic food web' pro- cess during the mid 1970 s to 1980 s that was shown when higher catches were obtained in parallel with a decline in $\mathrm{mTL}_{\mathrm{c}}$. Although a sequential addition mechanism due to the addition of new fisheries sensu Essington et al. (2006) may also have occurred (i.e. due to the increasing value of several invertebrate species and the number of boats that target them), the fishingdown process may have occurred mainly due to a decrease of demersal fish and an increase of invertebrates and small pelagic fish (Coll et al. 2007). This process could have been mitigated by the enrichment of the system due to nutrient loading until at least the early $1980 \mathrm{~s}$. These results regarding $\mathrm{mTL}_{\mathrm{c}}$ contrast with those reported for the Western Mediterranean fishery (Pinnegar et al. 2003). In this case, $\mathrm{mTL}_{\mathrm{c}}$ was reported to have decreased mainly due increasing landings of bivalve molluscs from mariculture and not due to changes in landings from fisheries.

Results highlighted changes in ecosystem functioning during the 1990s: decreasing nutrient input due to changes in environmental policy may have influenced the decline in biomass and catches during this period (although eutrophication was still high during the 1990s; Sangiorgi \& Donders 2004), in parallel with a continuous increase in fishing effort. Trophic spectra calculated from catch and data also showed this impoverishment of ecosystem biomass.

Unlike models and catch data, biomass estimates from scientific trawl surveys between 1982 and 2005 did not show the decrease in the $\mathrm{mTL}_{\mathrm{co}}$, probably due to the fact that fewer benthic invertebrate species were included in the database (Table A1). Commercial catches mainly include commercial invertebrate species, and also data from beam trawlers, which sample benthic invertebrates much more efficiently than otter trawls (used for scientific surveys). Beam trawlers have increased in number and engine power in the past (Pranovi et al. 2003).

In general, these results demonstrate that fishing impacts have increased in the Adriatic Sea over the last $30 \mathrm{yr}$, while the ecosystem has progressed towards an altered and depleted state. Correlation analysis confirmed the relationship between these changes and a fishing effort increase in the ecosystem, in addition to changes in the environment. This supports the Adriatic Sea being ranked as one of the ecosystems most impacted by fishing in a comparison with 19 other ecosystems when using multiple indicators, accounting for current states and recent trends (Coll et al. 2010, Link et al. 2010). The application of the $\mathrm{L}$ index, a new index of the ecosystem effects of fishing, to modelling results and global datasets (Libralato et al. 2008) also evidenced a high probability of ecosystem overfishing for the Adriatic Sea during the last 3 decades. 


\section{Multivariate framework for an ecosystem assessment}

The trajectory of PCA scores was similar under the analysis of both modelling results and surveys and catch data, and the combination of these data within a multivariate framework enabled us to delineate several key processes affecting the Adriatic Sea ecosystem at once and through time. These results showed that the main trajectory in the last 3 decades was characterized by a general decrease in biomass and catch, with some records of species proliferations. These changes happened in parallel with an increase in fishing effort and changes in various environmental parameters, such as an increase in the SST, decline in the inflow of highly saline Mediterranean water into the Adriatic Sea, and changes in the atmospheric pressure at sea-level (and most likely also changes in nutrient enrichment although not included in this analysis due to lacking data). Our study shows that the combination of multiple biotic and abiotic indicators is thus essential to understanding main changes on this marine ecosystem. These results can be complementary to traditional single-species fisheries assessments, while mechanistic tools such as modelling exercises may be useful in assessing whether this marine ecosystem could be brought to previous states or could be changed in specific ways (Link et al. 2002).

Acknowledgements. The authors acknowledge all colleagues who provided data and technical advice for of this work, in particular from the Istituto di Scienze Marine (CNR), Sede di Ancona (Italy): A. Artegiani, M. Azzali, N. Cingolani, G. Fabi, C. Froglia, M. E. Gramitto, and B. E. Morello; and A. Russo (Università Politecnica delle Marche), A. Di Natale (Aquastudio), S. Fonda Umani (Università di Trieste), D. Holcer (Natural History Museum of Zagreb), S. Libralato (Istituto Nazionale di Oceanografia e di Geofisica Sperimentale, Trieste), C. Piccinetti (Università di Bologna), R. Santolini (Università di Urbino), M. Zavatarelli (Università di Bologna) and B. Grbec (Institute of Oceanography and Fisheries of Split, Croatia). This work was made possible by a bilateral Cooperative-Agreement between the CNR (Italy) and the CSIC (Spain). The EU project SESAME contract no. 036949-2 that allowed the continuation of this work is greatly acknowledged. M.C. was supported financially by a postdoctoral fellowship from the Spanish Ministry of Science and Technology, and by the European Community Marie-Curie Postdoctoral Fellowship through the International Outgoing Fellowships (Call: FP7-PEOPLE-2007-4-1-IOF) to ECOFUN.

\section{LITERATURE CITED}

Affronte M, Scaravelli D (2001) Analysis of stranded sea turtles in the north-western Adriatic Sea. Zool Middle East 24:101-108

Agostini VN, Bakun A (2002) 'Ocean triads' in the Mediterranean Sea: physical mechanisms potentially structuring reproductive habitat suitability (with example application to European anchovy, Engraulis encrasicolus). Fish Oceanogr 11:129-142
Ainsworth CH, Pitcher TJ (2006) Modifying Kempton's species diversity index for use with ecosystem simulation models. Ecol Indic 6:623-630

Barmawidjaja DM, Vanderzwaan GJ, Jorissen FJ, Puskaric S (1995) 150 years of eutrophication in the northern Adriatic Sea: evidence from a benthic foraminiferal record. Mar Geol 122:367-384

Bearzi G, Holcer D, Notarbartolo di Sciara GN (2004) The role of historical dolphin takes and habitat degradation in shaping the present status of northern Adriatic cetaceans. Aquat Conserv Mar Freshw Ecosyst 14:363-379

Bombace G (1992) Fisheries of the Adriatic Sea. In: Colombo G, Ferrari I, Ceccherelli VU, Rossi R (eds) Marine eutrophication and population dynamics. 25th Eur Mar Biol Symp. Olsen \& Olsen, Fredensborg, p 379-389

Bombace G, Grati F (2007) Che succede alle risorse di pesca del Mediterraneo? Not Soc Ital Biol Mar 51:29-38

Bosc E, Bricaud A, Antoine D (2004) Seasonal and interannual variability in algal biomass and primary production in the Mediterranean Sea, as derived from 4 years of SeaWiFS observations. Global Biogeochem Cycles 18 GB1005 doi: 10.1029/2003GB002034

Christensen V (2000) Indicators for marine ecosystems affected by fisheries. Mar Freshw Res 51:447-450

Christensen V, Walters C (2004) Ecopath with Ecosim: methods, capabilities and limitations. Ecol Modell 172:109-139

Cingolani N, Kirkwood G, Arneri E, Santojanni A and others (2000) Discards from the Adriatic small pelagic fishery. Final report on European Community funded project, EU 97/065, IX

Cingolani N, Santojanni A, Arneri E, Belardinelli A, Giannetti G, Colella S, Donato F (2002a) Valutazione degli stocks pelagici di alici e sardine in Adriatico con metodi di dinamica di popolazione. Rapporto per il Ministero per le Politiche Agricole e Forestali, Rome

Cingolani N, Santojanni A, Arneri E, Belardinelli A, Giannetti G, Colella S, Donato F (2002b) Stock assessment of sardine (Sardina pilchardus, Walb.) in the Adriatic Sea. Biol Mar Mediterranea 9:82-88

Clarke KR, Gorley RN (2006) PRIMER v6: user manual/tutorial (Plymouth routines in multivariate ecological research). Primer-E, Plymouth

> Clarke KR, Warwick RM (2001) A further biodiversity index applicable to species lists: variation in taxonomic distinctness. Mar Ecol Prog Ser 216:265-278

Coll M, Santojanni A, Palomera I, Tudela S, Arneri E (2007) An ecological model of the Northern and Central Adriatic Sea: analysis of ecosystem structure and fishing impacts. J Mar Syst 67:119-154

Coll M, Lotze HK, Romanuk TN (2008a) Structural degradation in Mediterranean Sea food webs: testing ecological hypotheses using stochastic and mass-balance modelling. Ecosystems 11:939-960

Coll M, Palomera I, Tudela S, Dowd M (2008b) Food-web dynamics in the South Catalan Sea ecosystem (NW Mediterranean) for 1978-2003. Ecol Model 217:95-116

> Coll M, Palomera I, Tudela S (2009a) Decadal changes in a NW Mediterranean Sea food web in relation to fishing exploitation. Ecol Model 220:2088-2102

Coll M, Santojanni A, Palomera I, Arneri E (2009b) Food-web changes in the Adriatic Sea over the last three decades. Mar Ecol Prog Ser 381:17-37

Coll M, Shannon LJ, Yemane D, Link JS and others (2010) Ranking the ecological relative status of exploited marine ecosystems. ICES J Mar Sci 67:769-786

Cooper J, Borg JJ, Belda EJ, Papaconstantinou C, Sánchez A (2000) Mortalidad de aves marinas en palangres del mar 
mediterráneo y región Macaronésica: revisión y recomedaciones para el futuro, Vol 6. Simposio Mediterráneo sobre aves marinas. Conferencia sobre pesquerías, productividad marina y conservación de aves marinas. 11-15 Oct 2000, Benidorm

de Leiva Moreno JI, Agostini VN, Caddy JF, Carocci F (2000) Is the pelagic-demersal ratio from fishery landings a useful proxy for nutrient availability? A preliminary data exploration for the semi-enclosed seas around Europe. ICES J Mar Sci 57:1091-1102

Dulčić J, Grbec B, Lipej L (1999) Information on the Adriatic ichthyofauna: effect of water warming? Acta Adriat 40: 33-43

- Essington TE, Beaudreau AH, Wiedenmann J (2006) Fishing through marine food webs. Proc Natl Acad Sci USA 103: 3171-3175

Fonda Umani S (1996) Pelagic production and biomass in the Adriatic Sea. Sci Mar 60:65-77

> Gascuel D, Bozec YM, Chassot E, Colomb A, Laurans M (2005) The trophic spectrum: theory and practical applications. ICES J Mar Sci 62:443-452

Grbec B, Dulcic J, Morovic M (2002) Long-term changes in landings of small pelagic fish in the eastern Adriaticpossible influence of climate oscillations over the Northern Hemisphere. Clim Res 20:241-252

Grbec B, Morovi M, Zore-Armanda M (2003) Mediterranean oscillation and its relationship to salinity fluctuation in the Adriatic Sea. Acta Adriat 44:61-76

Grbec B, Vilibić I, Bajić A, Morović M, Bec Paklar G, Matić F, Dadić V (2007) Response of the Adriatic Sea to the atmospheric anomaly in 2003. Ann Geophys 25:835-846

Grbec B, Morovi M, Dul i J, Marasović I, Ninevi Ž (2008) Impact of the climatic change on the Adriatic Sea ecosystem. Fresenius Environ Bull 17:1-7

Hughes TP, Bellwood DR, Folke C, Steneck RS, Wilson J (2005) New paradigms for supporting the resilience of marine ecosystems. Trends Ecol Evol 20:380-386

Jennings S, Greenstreet S, Hill L, Piet G, Pinnegar J, Warr KJ (2002) Long-term trends in the trophic structure of the North Sea fish community: evidence from stable-isotope analysis, size-spectra and community metrics. Mar Biol 141:1085-1097

Jongman RHG, ter Braak CJF, van Tongeren OFR (1999) Data analysis in community and landscape ecology. Cambridge University Press, Cambridge

Jukić-Peladić S, Vrgoc N, Krstulovic-Sifner S, Piccinetti C, Piccinetti-Manfrin G, Marano G, Ungaro N (2001) Longterm changes in demersal resources of the Adriatic Sea: comparison between trawl surveys carried out in 1948 and 1998. Fish Res 53:95-104

Kempton RA, Taylor LR (1976) Models and statistics for species diversity. Nature 262:818-820

Libralato S, Pranovi F, Raicevich S, Da Ponte F and others (2004) Ecological stages of the Venice Lagoon analysed using landing time series data. J Mar Syst 51:331-344

Libralato S, Christensen V, Pauly D (2006) A method for identifying keystone species in food web models. Ecol Model 195:153-171

Libralato S, Coll M, Tudela S, Palomera I, Pranovi F (2008) Novel index for quantification of ecosystem effects of fishing as removal of secondary production. Mar Ecol Prog Ser 355:107-129

Lindeman RL (1942) The trophic-dynamic aspect of ecology. Ecology 23:399-418

Link JS, Brodziak JKT, Edwards SF, Overholtz WJ and others (2002) Marine ecosystem assessment in a fisheries management context. Can J Fish Aquat Sci 59:1429-1440
Link JS, Yemane D, Shannon LJ, Coll M and others (2010) Relating marine ecosystem indicators to fishing and environmental drivers: an elucidation of contrasting responses. ICES J Mar Sci 67:787-795

Marasović I, Grbec B, Morovi M (1995) Long-term production changes in the Adriatic. Neth J Sea Res 34:267-273

> Mattei N, Pellizzato M (1996) A population study on three stocks of a commercial Adriatic pectinid (Pecten jacobaeus). Fish Res 26:49-65

Morello EB, Arneri E (2009) Anchovy and sardine in the Adriatic Sea: an ecological review. Oceanogr Mar Biol Annu Rev 47:209-256

Odum WE, Heald EJ (1975) The detritus-based food web for an estuarine mangrove community. In: Cronin LE (ed) Estuarine research, Vol 1. Academic Press, New York, NY

Ott J (1992) The Adriatic benthos: problems and perspectives. In: Colombo G, Ferrari I, Ceccherelli VU, Rossi R (eds) Marine eutrophication and population dynamics. 25th Eur Mar Biol Symp. Olsen \& Olsen, Fredensborg, p 367-378

> Pauly D, Christensen V (1995) Primary production required to sustain global fisheries. Nature 374:255-257

Pauly D, Watson R (2005) Background and interpretation of the 'Marine Trophic Index' as a measure of biodiversity. Philos Trans R Soc B Biol Sci 360:415-423

> Pauly D, Christensen V, Dalsgaard J, Froese R, Torres F (1998) Fishing down marine food webs. Science 279:860-863

> Pauly D, Christensen V, Walters C (2000) Ecopath, Ecosim, and Ecospace as tools for evaluating ecosystem impact of fisheries. ICES J Mar Sci 57:697-706

Pinardi N, Arneri E, Crise A, Ravaioli M, Zavatarelli M (2006) The physical, sedimentary and ecological structure and variability of shelf areas in the Mediterranean Sea. In: Robinson AR, Brink KA (eds) The Sea, Vol 14. Harvard University Press, Cambridge, MA, p 1245-1331

Pinnegar JK, Polunin NVC, Badalamenti F (2003) Long-term changes in the trophic level of western Mediterranean fishery and aquaculture landings. Can J Fish Aquat Sci 60:222-235

> Power ME, Tilman D, Estes JA, Menge BA and others (1996) Challenges in the quest for keystones. Bioscience 46 : $609-620$

Pranovi F, Raicevich S, Franceschini G, Torricelli P, Giovanardi O (2001) Discard analysis and damage to nontarget species in the 'rapido' trawl fishery. Mar Biol 139: 863-875

> Pranovi F, Libralato S, Raicevich S, Granzotto A, Pastres R, Giovanardi O (2003) Mechanical clam dredging in Venice lagoon: ecosystem effects evaluated with a trophic massbalance model. Mar Biol 143:393-403

Riedl R (1983) Fauna and flora of the Mediterranean: a systematic marine guide for biologists and nature lovers. Verlag Paul Parey, Hamburg

Sangiorgi F, Donders TH (2004) Reconstructing 150 years of eutrophication in the north-western Adriatic Sea (Italy) using dinoflagellate cysts, pollen and spores. Estuar Coast Shelf Sci 60:69-79

Santojanni A, Arneri E, Belardinelli A, Cingolani N, Giannetti G (2001) Fishery and stock assessment of sardine Sardina pilchardus (WALB.) in the Adriatic Sea. Acta Adriat 42: 151-168

Santojanni A, Arneri E, Barry C, Belardinelli A, Cingolani N, Giannetti G, Kirkwood G (2003) Trends of anchovy (Engraulis encrasicolus, L.) biomass in the northern and central Adriatic Sea. Sci Mar 67:327-340

Santojanni A, Cingolani N, Arneri E, Kirkwood G and others (2005) Stock assessment of sardine (Sardina pilchardus, Walb.) in the Adriatic Sea, with an estimate of discards. Sci 
Mar 69:603-617

Santojanni A, Arneri E, Bernardini V, Cingolani N, Di Marco M, Russo A (2006a) Effects of environmental variables on recruitment of anchovy in the Adriatic Sea. Clim Res 31: 181-193

Santojanni A, Cingolani N, Arneri E, Belardinelli A, Giannetti G, Colella S, Donato F (2006b) Recruitment of sardine (Sardina pilchardus Walbaum 1792) in the Adriatic Sea and environmental factors. Biol Mar Mediterranea 13:158-166

Smith TM, Reynolds RW (2004) Improved extended reconstruction of SST (1854-1997). J Clim 17:2466-2477

Vrgoć N, Arneri E, Jukić-Peladić S, Krstulović Šifner S and others (2004) Review of current knowledge on shared demersal stocks of the Adriatic Sea, Vol 12. GCP/RER/ 010/ITA/TD-12. AdriaMed Technical Documents

Wieczorek SK, Campagnuolo S, Moore PG, Froglia C, Atkinson RJA, Gramitto ME, Bailey N (1999) The composition and fate of discards from the Nephrops norvegicus trawling in Scottish and Italian waters. Final report on European Community funded project, 96/092, Ancona

Zotier R, Bretagnolle V, Thibault JC (1999) Biogeography of the marine birds of a confined sea, the Mediterranean. J Biogeogr 26:297-313

Županović S, Jardas I (1989) Fauna i flora Jadrana: Jabucka Kotlina, Vol 4. Institut za Oceanografiju i Ribarstvo, Logos, Split

Appendix. Table A1. Number of species collected during scientific demersal trawl surveys (GRUND) by water depth and year, and by principal group (fish, crustaceans [crust] and mollusks [moll])

\begin{tabular}{|c|c|c|c|c|c|c|c|c|c|c|c|c|c|c|c|c|c|}
\hline \multirow{2}{*}{ Year } & \multicolumn{4}{|c|}{$\longrightarrow 0-50 \mathrm{~m} \longrightarrow$} & \multirow[b]{2}{*}{ Fish } & \multirow{2}{*}{\multicolumn{2}{|c|}{$\begin{array}{r}50-100 \mathrm{~m} \\
\text { Crust Moll }\end{array}$}} & \multirow[b]{2}{*}{ Total } & \multirow{2}{*}{ Fish } & \multirow{2}{*}{\multicolumn{2}{|c|}{$\begin{array}{l}100-200 \mathrm{~m} \\
\text { Crust Moll }\end{array}$}} & \multirow{2}{*}{$\overline{\text { Total }}$} & \multirow{2}{*}{ Fish } & \multirow{2}{*}{\multicolumn{2}{|c|}{$->200 \mathrm{~m}$}} & \multirow[b]{2}{*}{ Total } & \multirow{2}{*}{ Mean } \\
\hline & Fish & Crust & Moll & Total & & & & & & & & & & & Moll & & \\
\hline 1982 & 72 & 4 & 8 & 84 & 56 & 7 & 6 & 69 & 59 & 1 & 13 & 73 & 43 & 3 & 9 & 55 & 70 \\
\hline 1987 & 62 & 4 & 13 & 79 & 54 & 4 & 10 & 68 & 59 & 6 & 11 & 76 & 33 & 1 & 7 & 41 & 66 \\
\hline 1992 & 68 & 4 & 10 & 82 & 59 & 3 & 9 & 71 & 40 & 2 & 7 & 49 & 12 & 1 & 2 & 15 & 54 \\
\hline 1997 & 74 & 5 & 11 & 90 & 76 & 8 & 14 & 98 & 63 & 3 & 17 & 83 & 33 & 2 & 9 & 44 & 79 \\
\hline 2002 & 93 & 10 & 13 & 116 & 81 & 7 & 10 & 98 & 66 & 6 & 18 & 90 & 43 & 11 & 13 & 67 & 93 \\
\hline
\end{tabular}

Table A2. Linear trends of biomass estimates from scientific surveys, catch statistics and ecosystem models by species or group of species for the NC Adriatic Sea from 1975-1980 to early 2000s. Data in ( ): related to VPA estimates. Obs: observations, a = corrected for autocorrelation, $\mathrm{l}=$ normality violated, $\mathrm{n}=$ normality slightly violated. Ceph.: cephalopods, benthop.: benthopelagic, dem: demersal, inv: invertebrate. Significant values in bold

\begin{tabular}{|c|c|c|c|c|c|c|c|c|c|c|c|c|c|c|c|c|}
\hline \multirow{3}{*}{$\begin{array}{l}\text { Species } \\
\text { or group }\end{array}$} & \multirow{2}{*}{\multicolumn{4}{|c|}{$\begin{array}{l}\text { Biomass } \\
\text { surveys }\end{array}$}} & \multirow{2}{*}{\multicolumn{4}{|c|}{$\begin{array}{c}\text { Catch } \\
\text { statistics }\end{array}$}} & \multirow{2}{*}{\multicolumn{4}{|c|}{ Biomass }} & \multirow[t]{2}{*}{ Todels } & \multirow{2}{*}{\multicolumn{2}{|c|}{ Catch }} & \multirow[b]{3}{*}{ Obs } \\
\hline & & & & & & & & & & & & & & & & \\
\hline & Slope & $\mathrm{p}$ & $\mathrm{R}^{2}$ & Obs & Slope & $\mathrm{p}$ & $\mathrm{R}^{2}$ & Obs & Slope & $\mathrm{p}$ & $\mathrm{R}^{2}$ & Obs & Slope & $\mathrm{p}$ & $\mathrm{R}^{2}$ & \\
\hline \multicolumn{17}{|l|}{ Invertebrates } \\
\hline Crabs & -0.09 & 0.01 & 0.50 & $\mathrm{a}$ & 0.10 & 0.00 & 0.76 & $\mathrm{a}$ & -0.07 & 0.06 & 0.46 & $\mathrm{a}$ & 0.02 & 0.76 & 0.00 & $a_{1} l$ \\
\hline Shrimps & 0.08 & 0.00 & 0.39 & $\mathrm{n}$ & 0.02 & 0.56 & 0.02 & $\mathrm{a}, \mathrm{n}$ & -0.07 & 0.07 & 0.48 & $\mathrm{a}$ & -0.03 & 0.58 & 0.08 & $a, l$ \\
\hline Norway lobster & -0.04 & 0.23 & 0.08 & & 0.00 & 0.97 & 0.00 & $\mathrm{a}$ & -0.08 & 0.03 & 0.59 & $\mathrm{a}$ & 0.00 & 0.93 & 0.01 & $a_{1}$, \\
\hline Benthic ceph. & -0.06 & 0.03 & 0.23 & & -0.02 & 0.61 & 0.02 & $\mathrm{a}$ & -0.09 & 0.00 & 0.81 & $\mathrm{a}$ & -0.06 & 0.12 & 0.53 & $\mathrm{a}$ \\
\hline Benthop. ceph. & 0.02 & 0.51 & 0.05 & $\mathrm{a}$ & -0.04 & 0.33 & 0.16 & $\mathrm{a}, \mathrm{n}$ & -0.08 & 0.01 & 0.66 & $\mathrm{a}$ & -0.05 & 0.21 & 0.39 & $\mathrm{a}$ \\
\hline Other benthic inv & -0.01 & 0.70 & 0.01 & $\mathrm{n}$ & 0.04 & 0.43 & 0.09 & $\mathrm{a}$ & -0.08 & 0.01 & 0.66 & a & -0.05 & 0.22 & 0.44 & a \\
\hline \multicolumn{17}{|l|}{ Demersal fish } \\
\hline Hake & 0.05 & 0.35 & 0.04 & $\mathrm{a}$ & -0.10 & 0.00 & 0.62 & & -0.11 & 0.00 & 0.84 & $\mathrm{a}$ & -0.05 & 0.17 & 0.26 & $a_{1} l$ \\
\hline Other gadiforms & -0.06 & 0.03 & 0.21 & $\mathrm{n}$ & -0.03 & 0.48 & 0.02 & $\mathrm{a}, \mathrm{n}$ & -0.10 & 0.00 & 0.75 & $\mathrm{a}, \mathrm{n}$ & -0.06 & 0.18 & 0.31 & $\mathrm{a}, \mathrm{l}$ \\
\hline Anglerfish & -0.09 & 0.01 & 0.36 & $\mathrm{a}$ & -0.06 & 0.16 & 0.37 & a & -0.11 & 0.00 & 0.85 & $\mathrm{a}$ & -0.11 & 0.00 & 0.92 & $\mathrm{a}$ \\
\hline Conger eel & -0.02 & 0.62 & 0.02 & $\mathrm{a}$ & -0.09 & 0.00 & 0.47 & & -0.11 & 0.00 & 0.88 & $\mathrm{a}$ & -0.06 & 0.09 & 0.35 & $\mathrm{a}, \mathrm{n}$ \\
\hline Flatfish & -0.09 & 0.00 & 0.43 & & -0.07 & 0.06 & 0.29 & $\mathrm{a}$ & -0.11 & 0.00 & 0.87 & $\mathrm{a}$ & -0.11 & 0.00 & 0.95 & $\mathrm{a}$ \\
\hline Red mullets & 0.04 & 0.16 & 0.10 & $\mathrm{n}$ & -0.05 & 0.05 & 0.16 & & -0.10 & 0.00 & 0.82 & $\mathrm{a}$ & -0.05 & 0.20 & 0.37 & $\mathrm{a}, \mathrm{n}, \mathrm{l}$ \\
\hline Other dem. fishes & $s-0.07$ & 0.02 & 0.41 & $\mathrm{a}$ & -0.09 & 0.00 & 0.56 & & -0.12 & 0.00 & 0.90 & $\mathrm{a}, \mathrm{n}$ & -0.08 & 0.01 & 0.71 & $\mathrm{a}$ \\
\hline Dem. sharks & -0.01 & 0.85 & 0.00 & $a, l$ & -0.07 & 0.06 & 0.38 & $\mathrm{a}$ & -0.11 & 0.00 & 0.90 & $\mathrm{a}$ & -0.06 & 0.13 & 0.41 & $\mathrm{a}$ \\
\hline Dem. skates & -0.06 & 0.05 & 0.19 & & -0.09 & 0.00 & 0.45 & $\mathrm{a}$ & -0.09 & 0.00 & 0.72 & $\mathrm{a}$ & -0.03 & 0.61 & 0.09 & a \\
\hline \multicolumn{17}{|l|}{ Pelagic fish } \\
\hline Anchovy & $\begin{array}{c}0.003 \\
(-0.037)\end{array}$ & $\begin{array}{c}0.927 \\
(0.395)\end{array}$ & $\begin{array}{c}0.000 \\
(0.186)\end{array}$ & $(a, n, l)$ & ) 0.00 & 0.97 & 0.09 & $\mathrm{a}$ & -0.10 & 0.00 & 0.73 & $\mathrm{a}$ & -0.04 & 0.31 & 0.18 & $\mathrm{a}$ \\
\hline Sardine & $\begin{array}{r}0.011 \\
(-0.051)\end{array}$ & $\begin{array}{c}0.729 \\
(0.135)\end{array}$ & $\begin{array}{c}0.006 \\
(0.537)\end{array}$ & $(a, n, l)$ & -0.05 & 0.08 & 0.45 & $\mathrm{a}$ & -0.06 & 0.10 & 0.51 & $\mathrm{a}, \mathrm{l}$ & -0.04 & 0.25 & 0.19 & $\mathrm{a}, \mathrm{n}$ \\
\hline $\begin{array}{l}\text { Other small } \\
\text { pelagic fish }\end{array}$ & -0.03 & 0.34 & 0.05 & & -0.05 & 0.29 & 0.28 & $\mathrm{a}$ & -0.10 & 0.00 & 0.84 & a & -0.10 & 0.00 & 0.77 & $\mathrm{a}$ \\
\hline Horse mackerel & -0.05 & 0.07 & 0.16 & & -0.11 & 0.00 & 0.64 & $\mathrm{a}$ & -0.10 & 0.00 & 0.75 & $\mathrm{a}$ & -0.03 & 0.37 & 0.07 & $\mathrm{a}$ \\
\hline Mackerel & 0.06 & 0.08 & 0.30 & $\mathrm{a}, \mathrm{n}$ & -0.10 & 0.00 & 0.58 & $\mathrm{a}$ & -0.07 & 0.02 & 0.31 & $\mathrm{a}, \mathrm{n}$ & 0.05 & 0.11 & 0.17 & $\mathrm{a}$ \\
\hline Benthop. fish & -0.71 & 0.04 & 0.22 & $\mathrm{a}, \mathrm{n}$ & -0.05 & 0.24 & 0.31 & $\mathrm{a}$ & -0.10 & 0.00 & 0.70 & $\mathrm{a}$ & -0.03 & 0.15 & 0.083 & \\
\hline
\end{tabular}

